\title{
Computing the daily reproduction number of COVID-19 by inverting the renewal equation
}

\author{
Luis Alvarez $^{\mathrm{a}, 1}$, Miguel Colom $^{\mathrm{b}}$, Jean-David Morel ${ }^{\mathrm{c}}$, and Jean-Michel Morel ${ }^{\mathrm{b}}$ \\ ${ }^{a}$ CTIM. Departamento de Informática y Sistemas, Universidad de Las Palmas de Gran Canaria. Spain; ${ }^{b}$ Université Paris-Saclay, ENS Paris-Saclay, CNRS, Centre Borelli, \\ F-94235, Cachan, France.; ' ${ }^{c}$ Laboratoire de Physiologie Intégrative et Systémique Ecole Polytechnique Fédérale de Lausanne, Al 1144 Station 15 CH-1015 Lausanne \\ Switzerland
}

\begin{abstract}
The COVID-19 pandemic has undergone frequent and rapid changes in its local and global infection rates, driven by governmental measures, or the emergence of new viral variants. The reproduction number $R_{t}$ indicates the average number of cases generated by an infected person at time $t$ and is a key indicator of the spread of an epidemic. A timely estimation of $R_{t}$ is a crucial tool to enable governmental organizations to adapt quickly to these changes and assess the consequences of their policies. The EpiEstim method is the most widely accepted method for estimating $R_{t}$. But it estimates $R_{t}$ with a delay of several days. Here, we propose a new method, Epilnvert, that shows good agreement with EpiEstim, but that provides estimates of $R_{t}$ up to 9 days in advance. We show that $R_{t}$ can be estimated by inverting the renewal equation linking $R_{t}$ with the observed incidence curve of new cases, $i_{t}$. Our signal processing approach to this problem yields both $R_{t}$ and a restored $i_{t}$ corrected for the "weekend effect" by applying a deconvolution + denoising procedure. The implementations of the Epilnvert and EpiEstim methods are fully open-source and can be run in real-time on every country in the world, and every US state through a web interface at www.ipol.im/ern.
\end{abstract}

COVID-19 | Renewal equation | Reproduction number | Integral equations

The reproduction number $R_{t}$ is a key epidemiological parameter evaluating transmission rate of a disease over time. It is defined as the average number of new infections caused by a single infected individual at time $t$ in a partially susceptible population (1). $R_{t}$ can be computed from the daily observation of the incidence curve $i_{t}$, but requires empirical knowledge of the probability distribution $\Phi_{s}$ of the delay between two infections $(2,3)$.

There are two different models for the incidence curve and its corresponding infection delay $\Phi$. In a theoretical model, $i_{t}$ would represent the real daily number of new infections, and $\Phi_{s}$ is sometimes called generation time $(4,5)$ and represents the probability distribution of the time between infection of a primary case and infections in secondary cases. In practice, neither parameter is easily observable because the infected are rarely detected before the appearance of symptoms and tests will be negative until the virus has multiplied over several days. What is routinely recorded by health organizations is the number of new detected, incident cases. When dealing with this real incidence curve, $\Phi_{s}$ is called serial interval $(4,5)$. The serial interval is defined as the delay between the onset of symptoms in a primary case and the onset of symptoms in secondary cases (5).

$R_{t}$ is linked to $i_{t}$ and $\Phi$ through the renewal equation, first formulated for birth-death processes in a 1907 note of Alfred
Lotka (6). We adopt the Nishiura et al. formulation $(7,8)$,

$$
i_{t}=\sum_{s=f_{0}}^{f} R_{t-s} i_{t-s} \Phi_{s} \quad \text { for } t=0, . ., t_{c}
$$

where $t_{c}$ represents the current time (the last time at which $i_{t}$ was available), $f_{0}$ and $f$ are the maximal and minimal observed times between a primary and a secondary case.

It is important to note that secondary infections are sometimes detected before primary ones, and therefore the minimum delay $f_{0}$ is generally negative (see Fig. 2). Equation [1] does not yield an explicit expression for $R_{t}$. Yet, an easy solution can be found for a simplified version of the renewal equation proposed in Cori et al in (5).

$$
i_{t}=R_{t} \sum_{s=f_{0}}^{f} i_{t-s} \Phi_{s}
$$

by this equation, $R_{t}$ is derived at time $t$ from the past incidence values $i_{t-s}$ by a simple division, with the assumption that $f_{0} \geq 0$ :

$$
R_{t}=\frac{i_{t}}{\sum_{s=f_{0}}^{f} i_{t-s} \Phi_{s}} .
$$

This method, implemented by the EpiEstim software, is highly recommended in a very recent review (10) signed by representatives from ten different epidemiological labs from several

\section{Significance Statement}

Based on a signal processing approach we propose a method to compute the reproduction number $R_{t}$, the transmission rate of an epidemic over time. $R_{t}$ is estimated by minimizing a functional that enforces: (i) the ability to produce an incidence curve $i_{t}$ corrected of the weekly periodic bias produced by the "weekend effect", obtained from $R_{t}$ through a renewal equation ; (ii) the regularity of $R_{t}$. A good agreement is found between our $R_{t}$ estimate and the one provided by the currently accepted method, EpiEstim, except our method predicts $R_{t}$ almost nine days closer to the present. We provide the mathematical arguments for this shift. Both methods, applied every day on each country, can be compared at www.ipol.im/ern.

L. Alvarez and J-M. Morel designed and performed research and experiments and wrote the paper. L. Alvarez implemented the method. M. Colom built the online interface and collected and processed data. J.D. Morel rewrote parts and designed the statistical analysis and presentation of the results.

The authors declare no competing interests

${ }^{1}$ Luis Alvarez. E-mail: lalvarez@ulpgc.es 

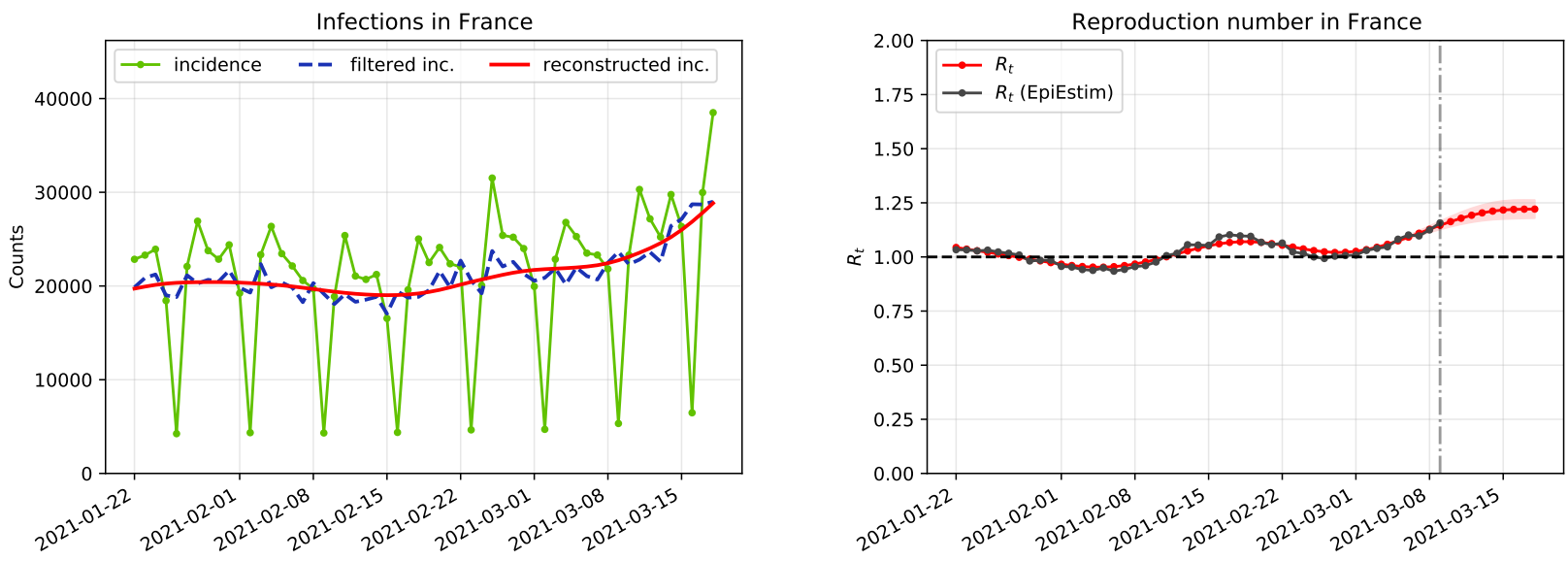

Fig. 1. Illustration of the Epilnvert method on the France incidence curve of new cases. On the left: in green, the raw oscillating curve of incident cases up to March 26 , 2021. In blue, the incidence curve after correction of the "week-end bias". In red, the incidence curve simulated from $R_{t}$ after the inversion of the renewal equation. On the right: in black, $R_{t}$, the reproduction number estimated by the current EpiEstim method, adopted by most health experts (9). Estimating its value every day guides the health policy of each country. Having $R_{t}$ larger than 1, as it is the case for France on March 26, 2021 means that the pandemic is expanding. In red, the estimation of $R_{t}$ by the Epilnvert method. This estimate, obtained by compensating the week-end bias and inverting the integral equation, predicts $R_{t}$ nearly nine days closer to the present than EpiEstim.

continents. A detailed description of EpiEstim can be found in the supporting information. Equation [2] is the standard method, and of widespread use. In its stochastic formulation, the first member $i_{t}$ of Equation [2] is assumed to be a Poisson variable, and the second member of this equation is interpreted as the expectation of this Poisson variable. This leads to a maximum likelihood estimation strategy to compute $R_{t}$ (see $(5,11-14))$.

Comparing Equations [2] and [1] shows that the second equation is derived from the first by assuming $R_{t}$ constant on the serial interval $\left[t-f, t-f_{0}\right]$. Replacing $R_{t-s}$ by $R_{t}$ in Equation [1] indeed yields Equation [2]. A more accurate interpretation of the quotient on the right of Equation [3] would be

$$
R_{t-\mu}=\frac{i_{t}}{\sum_{f_{0}}^{f} i_{t-s} \Phi_{s}},
$$

where $\mu$ is a central value of the probability distribution of the serial interval $\Phi$ that could be, for instance, the median or the mean. In the Ma et al. (15) estimate of the serial interval for Covid-19, we have $\mu \simeq 5.5$ for the median and $\mu \simeq 6.7$ for the mean. This supports that EpiEstim estimates $R_{t}$ with an average delay of more than 5 days.

In practice, the delay is even longer, due to the way the sliding average of the incidence is calculated. Indeed, as illustrated in Figure 1 the raw data of the incidence curve $i_{t}$ can oscillate strongly with a seven-day period. This oscillation has little to do with the Poisson noise used in most aforementioned publications. Government statistics are affected by changes of testing and polling policies and by week-end reporting delays. These recording delays and subsequent rash corrections result in impulse noise, and a strong weekly periodic bias observable on the incidence curve (in green) on the left of the figure 1.

To reliably estimate the reproduction number, a regularity constraint on $R_{t}$ is needed. Cori et al., initiators of the EpiEstim method (5) use as regularity constraint the assumption that $R_{t}$ is locally constant in a time window of size $\tau$ ending at time $t$ (usually $\tau=7$ days). This results in smoothing the incidence curve with a sliding mean over 7 days. This assumption has two limitations: it causes a significant resolution loss, and an additional $\frac{\tau}{2}=3.5$ backward shift in the estimation of $R_{t}$, given that $R_{t}$ is assumed constant in $[t-\tau, t]$.

In summary, the computation of $R_{t}$ raises three challenges:

1. The renewal equation for incident cases involves future values of $i_{t}$, those for $t+1, \cdots, t-f_{0}$.

2. A simplification of the renewal equation [1] leads the standard method to estimate $R_{t}$ with a backward shift of more than 5 days.

3. Smoothing of the week-end effect causes a further 3.5 days shift.

These cumulative backward shifts cause a time delay of more than 8.5 days. In other terms, the value of $R_{t}$ computed at time $t$ refers approximately to $R_{t-9}$.

Here, we address these three issues by proposing a method that inverts Equation [1] without simplifying it. The result of EpiInvert, the inversion method developed here, is illustrated in Figure 1 (right), where the EpiEstim result (in black) is superposed with the estimate (in red) of $R_{t}$ by EpiInvert. After registering both, the black EpiEstim curve stops nine days before EpiInvert, the red curve (our estimate). We found, using the incidence curve of 70 countries, that the optimal shift between the EpiEstim and EpiInvert $R_{t}$ estimates is about $8.3 \pm 0.5$ days and that the RMSE approximation error between both estimates is just about $3.6 \% \pm 1.9 \%$.

Indeed, the general integral equation [1] is a functional equation in $R$. Integral equations have been previously used to estimate $R_{t}$ : in (16), the authors estimate $R_{t}$ as the direct deconvolution of a simplified integral equation where $i_{t}$ is expressed in terms of $R_{t}$ and $i_{t}$ in the past, without using the serial interval. Such inverse problems involving noise and a reproducing kernel can be resolved through the TikhonovArsenin (17) variational approach involving a regularization term. This method is widely used to solve integral equations and convolutional equations (18). The solution of the equation is estimated by an energy minimization. The regularity of the solution is obtained by penalizing high values of the derivative 


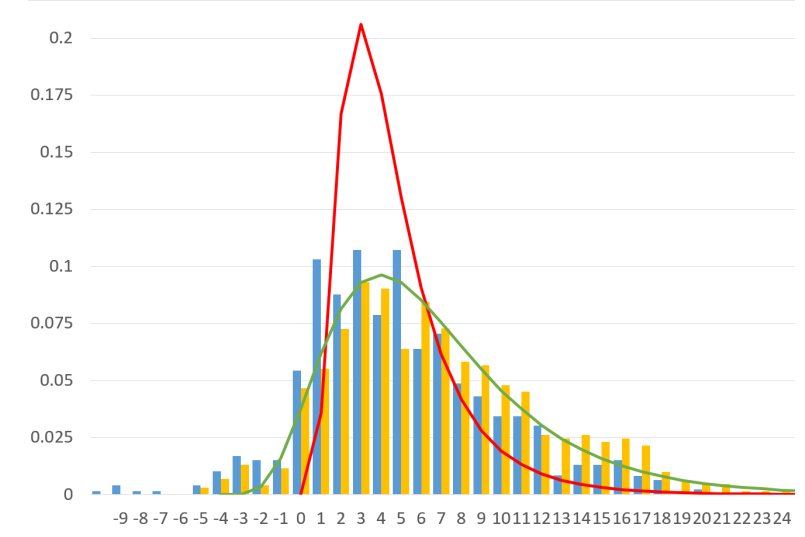

Fig. 2. Serial intervals used in our experiments: the discrete one proposed by Du et al. in (19) (solid bars in blue), the serial interval proposed by Ma et al. (15) (solid bars in orange) and its shifted log-normal approximation (in green), finally a log-normal approximation of the serial interval proposed by Nishiura et al. in (20) (in red).

of the solution. Our variational formulation includes the correction of the weekly periodic bias, or "weekend effect". The standard way to deal with a weekly periodic bias is to smooth the incidence curve by a seven days sliding mean. This implicitly assumes that the periodic bias is additive. The present study supports the idea that this bias is better dealt with as multiplicative. In the variational framework, the periodic bias is therefore corrected by estimating multiplicative periodic correction factors. This is illustrated on the left graphic of Fig. 1 where the green oscillatory curve is transformed into the blue filtered curve by the same energy minimization process that also computes $R_{t}$ (on the right in red) and reconstructs the incidence curve up to present (on the left, in red).

\section{Available serial interval functions for SARS-CoV-2}

As we saw, the serial interval in epidemiology refers to the time between successive observed cases in a chain of transmission. $\mathrm{Du}$ et al. in (19) define it as "the time duration between a primary case (infector) developing symptoms and secondary case (infectee) developing symptoms."

$\mathrm{Du}$ et al. in (19) obtained the distribution of the serial interval by a careful inquiry on 468 pairs of patients where one was the probable cause of the infection of the other. The serial distribution $\Phi$ obtained in (19) has a significant number of cases on negative days, meaning that the infectee had developed symptoms up to $f_{0}=10$ days before the infector. In addition to this first serial interval, we test a serial interval obtained by Nishiura et al. in (20) using 28 cases, which is approximated by a log-normal distribution, and a serial interval obtained by Ma et al. in (15) using 689 cases. As proposed by the authors this serial interval has been approximated by a shifted log-normal to take into account the cases in the negative days. In Fig. 2 we show the profile of the three serial intervals. There is good agreement of the serial intervals obtained by Du et al. (19) and Ma et al. (15)* Note that $f_{0}=-4$ for the Ma et al. serial interval, $f_{0}=0$ for Nishiura et al. and $f_{0}=-10$ for Du et al. The discrete support of $\Phi$ is therefore contained in the interval $\left[f_{0}, f\right]$.

* In the online interface (www.ipol.im/ern) the users can, optionally, upload their own distribution for the serial interval.

\section{Computing $R_{t}$ by a variational method}

We consider two versions of the general renewal equation [1] given by

$$
i_{t}=F(R, i, \Phi, t) \quad \text { for } t=0, . ., t_{c}, \quad[5] \quad 159
$$

where

$$
F=F_{1} \equiv R_{t} \sum_{s=f_{0}}^{f} i_{t-s} \Phi_{s} ; \quad F=F_{2} \equiv \sum_{s=f_{0}}^{f} i_{t-s} R_{t-s} \Phi_{s} . \quad[6]
$$

$F_{2}$ corresponds to the general renewal equation and $F_{1}$ to the simplifed Cori et al. (5) version. The very same formula can also be derived for the classic Wallinga Teunis method (4), as shown in the supporting information. This last method is widely used to compute $R_{t}$ retrospectively.

Correcting the week-end effect We must first formulate a compensation for the weekend effect, which in most countries is stationary, strong, and the main cause of discrepancy between $i_{t}$ and its expected value $F(i, R, \Phi, t)$. To remove the weekend effect we estimate periodic multiplicative factors defined by a vector $\mathbf{q}=\left(q_{0}, q_{1}, q_{2}, q_{3}, q_{4}, q_{5}, q_{6}\right)$.

The variational framework we propose to estimate $R_{t}$ is therefore given by the minimization of the energy

$$
\begin{aligned}
E\left(\left\{R_{t}\right\} ; \mathbf{q}\right)= & \sum_{t=0}^{t_{c}}\left(\frac{q_{t \% 7} i_{t}-F\left(\left\{q_{t \% 7} i_{t}\right\}, R, \Phi, t\right)}{p_{50}(i)}\right)^{2}+ \\
& w \sum_{t=1}^{t_{c}}\left(R_{t}-R_{t-1}\right)^{2}
\end{aligned}
$$

where $t \% 7$ denotes the remainder of the Euclidean division of $t$ by $7, t=0$ represents the beginning of the epidemic spread and $t_{c}$ the current day.

The weekend effect has varied over the course of the pandemic. Hence, for the estimate of $\mathbf{q}$ it is better to use a time interval $\left[t_{c}-T+1, T\right]$ where $T$ is fixed in the experiments to $T=56$ ( 8 weeks). This two months time interval is long enough to avoid overfitting and small enough to ensure that the testing policy has not changed too much. The optimization of $R_{t}$ is instead performed through the whole time interval $\left[0, t_{c}\right]$. The corrected value $\hat{i}_{t}=q_{t \% 7} i_{t}$ amounts to a deterministic attenuation of the weekend effect on $i_{t}$. An obvious objection is that this correction might not be mean-preserving. To preserve the number of accumulated cases in the period of estimation, we therefore add the constraint

$$
\sum_{t=t_{c}-T+1}^{t_{c}} i_{t}=\sum_{t=t_{c}-T+1}^{t_{c}} \hat{i}_{t}=\sum_{t=t_{c}-T+1}^{t_{c}} q_{t \% 7} i_{t}
$$

to the minimization problem [7].

In that way, the multiplication by the factor $q_{t \% 7}$ produces a redistribution of the cases $i_{t}$ during the period of estimation, but it does not change the global amount of cases. In Equation [7], $p_{50}(i)$ is the 50th percentile (the median) of $\left\{i_{t}\right\}_{t=t_{c}-T+1, \ldots, t_{c}}$ used to normalize the energy with respect to the size of $i_{t}$. The first term of $E$ is a data fidelity term which forces the renewal equation [5] to be satisfied as much as possible. The second term is a classic Tikhonov-Arsenin regularizer of $R_{t}$. 
The regularization weight. The regularization weight $w \geq 0$ is a dimensionless constant weight fixing the balance between the data adjustment term and the regularization term.

Boundary conditions of the variational model. Since $t=0$ is the beginning of the epidemic spread where the virus runs free one is led to use an estimate of $R_{0}=R 0$ based on the basic reproduction number $R 0$. (In the supporting information we present a basic estimation of $R 0$ from the initial exponential growth rate of the epidemic obtained as in (21)), therefore, to solve Equation [7], we add the boundary condition $R_{0}=$ $R 0$. The proposed inversion model provides an estimation of $R_{t}$ up to the current day $t_{c}$. Yet if $f_{0}<0$, the functional [7] involves a few future values of $R_{t}$ and $i_{t}$ for $t_{c} \leq t \leq$ $t_{c}-f_{0}$. These values are unknown at present time $t_{c}$. We use a basic linear regression using the last seven values of $i_{t}$ to extrapolate the values of $i_{t}$ beyond $t_{c}$. We prove in the supporting information, that the boundary conditions and the choice of the extrapolation procedure have a minor influence in the estimation of $R_{t}$ in the last days when minimizing [7].

All of the experiments described here can be reproduced with the online interface available at www.ipol.im/ern. This online interface allows one to assess the performance of the method applied to the total world population and to any country and any state in the USA, with the last date updated to the current date. We detail our daily sources in the supporting information.

An empirical confidence interval for $R_{t}$. In absence of a statistical model on the distribution of $R_{t}$, no theoretical a priori confidence interval for this estimate can be given. Nevertheless, a realistic confidence interval is obtained by the following procedure:

1. Compute $\left\{R^{k}(t)\right\}_{t \in\left[0, t_{c}-k\right]}$ by minimizing [7] for $k=$ $1,2,3$, using the data sequence up to $t_{c}-k$.

2. Compute for each $t \in\left[0, t_{c}\right]$ a confidence bound of $R_{t}$ with respect to its value $R^{1}(t), R^{2}(t)$ and $R^{3}(t)$ in the three preceding days given by

$$
\sigma(t)=\sqrt{\frac{\sum_{k=1}^{3}\left(R_{t}-R^{k}(t)\right)^{2}}{3}},
$$

where $R^{k}(t)$ in $\left(t_{c}-k, t_{c}\right]$ are obtained by linear extrapolation.

We then define a conservative empirical confidence interval as $\left[R_{t}-2 \cdot \sigma(t), R_{t}+2 \cdot \sigma(t)\right]$. This interval is displayed for each $t$ in the online algorithm www.ipol.im/ern and has the aspect of a fattened curve above and below $R_{t}$.

Efficiency measure of the weekly bias correction. We estimate the correction of the weekly periodic bias by the efficiency measure

$$
\mathcal{I}=\sqrt{\frac{\sum_{t=t_{c}-T+1}^{t_{c}}\left(\hat{i}_{t}-F(\hat{i}, R, \Phi, t)\right)^{2}}{\sum_{t=t_{c}-T+1}^{t_{c}}\left(i_{t}-F(i, R 1, \Phi, t)\right)^{2}}} .
$$

$\mathcal{I}$ represents the reduction factor of the RMSE between the incidence curve and its estimate using the renewal equation after correcting the week-end bias. $\hat{i}_{t}=i_{t} q_{t \% 7}$ and $R$ are the optimal values for the energy [7] and $R 1$ denotes the $R$ estimate without correction of the weekly bias. The value of $\mathcal{I}$ can be used to assess whether it is worth applying the correction of the weekly periodic bias to a given country in a given time interval.

Estimation of the temporal shift between EpiEstim and EpiInvert. In what follows, we will denote by $R_{t}^{i}$ the EpiEstim estimation of the reproduction number by Cori et al. in (5), detailed in the supporting information. As we have argued above, we expect a significant temporal shift between $R_{t}$ and $R_{t}^{i}$, of the order of 9 days. This expectation is strongly confirmed by the experimental results, and can be checked by applying the proposed method to any country using the online interface available at www.ipol.im/ern. In summary, the time shift between both methods should be a half-week (3.5 days) for $F \equiv F_{1}$ and by Equation [4] of about $\mu+3.5 \simeq 9$ for $F \equiv F_{2}$. This will be verified experimentally by computing the shift $\tilde{t}$ between $R_{t}^{i}$ and $R_{t}$ yielding the best RMSE between both estimates:

$$
\tilde{t}=\arg \min _{t \in[0,12]} \mathcal{S}(t) \equiv \sqrt{\frac{\sum_{k=t_{c}-T+1}^{t_{c}}\left(R_{k-t}-R_{k}^{i}\right)^{2}}{T}}
$$

where $T=56$ ( 8 weeks) and where we evaluate $R_{k-t}$ for non-integer values of $k-t$ by linear interpolation.

\section{Summary of the algorithm parameters and options.}

- choice of the serial interval : the default options are the serial intervals obtained by Ma et al. (we use the shifted log-normal approximation), Nishiura et al. and Du et al.. The users can also upload their own serial interval;

- choice of the renewal equation used, $F \equiv F_{1}$ or $F \equiv F_{2}$;

- $w$ : regularization weight, with default values $w=5$ for $F \equiv F_{1}$ and $w=5.5$ for $F \equiv F_{2}$;

- Correction of the weekly periodic bias (option by default)

Note that the regularization weight $w$ is the only numerical mandatory parameter.

Summary of the output displayed at www.ipol.im/ern. First we draw two charts. In the first one we draw $R_{t}$ and $R_{t}^{i}$ shifted back $\tilde{t}$ days where $\tilde{t}$ is defined in [11]. $R_{t}$ is surrounded by a shaded area that represents the above defined empirical confidence interval. In the second chart, we draw the initial incidence curve $i_{t}$ in green, the incidence curve after the correction of the weekly periodic bias $\hat{i}_{t}=i_{t} q_{t \% 7}$ in blue, and the evaluation of the renewal equation given by $t \rightarrow F(\hat{i}, R, \Phi, t)$ in red. For each experiment we also compute :

1. $R_{t_{c}}$ : last available value of the EpiInvert $R_{t}$ estimate.

2. $R_{t_{c}}^{i}$ : last available value of the EpiEstim estimate $R_{t}^{i}$.

3. $\tilde{t}$ : optimal shift (in days) between $R$ and $R^{i}$ defined in [11].

4. $\mathcal{S}(\tilde{t})$ : RMSE between $R$ and $R^{i}$ shifted back $\tilde{t}$ days (defined in [11]).

5. $\mathcal{V}(i)$ : variability of the original incidence curve, $i_{t}$, given by :

$$
\mathcal{V}(i) \equiv \frac{\left\|i^{\prime}\right\|_{L^{1}\left[t_{c}-T, t_{c}\right]}}{\|i\|_{L^{1}\left[t_{c}-T, t_{c}\right]}} \approx \frac{\sum_{t=t_{c}-T+1}^{t_{c}}\left|i_{t}-i_{t-1}\right|}{\sum_{t=t_{c}-T+1}^{t_{c}} i_{t}}
$$

6. $\mathcal{V}(\hat{i})$ : variability of the filtered incidence $\hat{i}_{t}$ after the correction of the weekly periodic bias. 


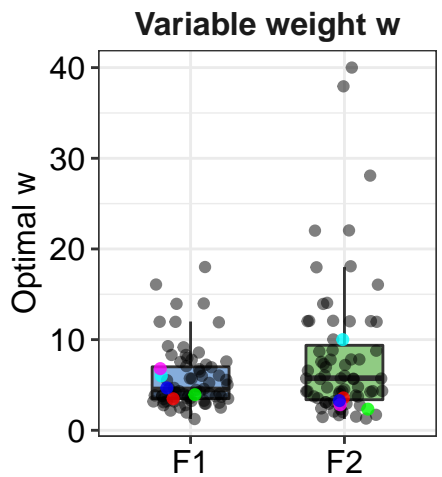

Fig. 3. Distribution of $w$ for $F_{1}$ and $F_{2}$ when the regularization weight $w$ and the delay $\tilde{t}$ are optimized independently for each country to minimize the average error $\mathcal{S}(\tilde{t})$ between the EpiEstim and the Epilnvert methods on a time lapse of 56 days. France in blue, Japan in green, Peru in cyan, South Africa in magenta, USA in red.

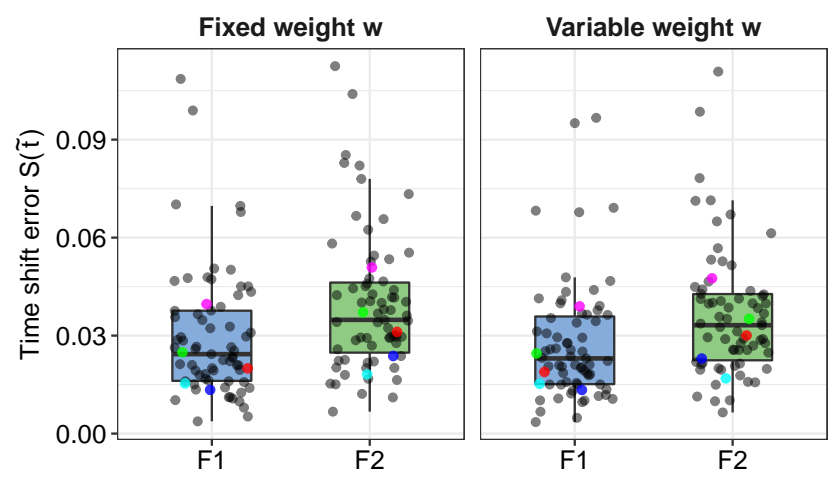

Fig. 4. Average error $\mathcal{S}(\tilde{t})$ over 56 consecutive days of the error between the EpiEstim and the Epilnvert estimates of $R_{t}$ for each country. France in blue, Japan in green, Peru in cyan, South Africa in magenta, USA in red.

7. $\mathcal{I}$ : reduction factor of the RMSE error between the incidence curve and its estimate using the renewal equation after the correction of the weekly periodic bias (defined in $[10])$.

8. $\mathbf{q}=\left(q_{0}, . ., q_{6}\right)$ : the correction coefficients of the weekly periodic bias ( $q_{6}$ corresponds to the current time $t_{c}$ ).

\section{Results}

To estimate a reference value for the regularization parameter $w$ we used the incidence data up to Saturday March 18, 2021 for the 70 countries showing the larger number of cases. For each country, we optimized the RMSE $\mathcal{S}(\tilde{t})$ between $R$ and $R^{i}$ shifted back $\tilde{t}$ days (defined in [11]). This optimization was performed with respect to $w$ and $\tilde{t}$. The goal was to fix $w$, the only parameter of the method so that the result of EpiInvert is as close as possible to EpiEstim in the days where both methods predict $R_{t}$. The second goal of this optimization was to estimate the effective time shift $\tilde{t}$ between both methods.

In Fig. 3 we show the box plot of the distribution of $w$ for $F_{1}$ and $F_{2}$ when $w$ was optimized independently for each country to minimize the average error over 56 days between the EpiEstim and the EpiInvert methods. The mean $w$ was $5.5 \pm 2.4 \%$ for $F_{1}$ and $5.9 \pm 2.9 \%$ for $F_{2}$ which indicated that a common value of $w$ could be fixed for all countries. Here and in all figures to follow, each dot represents a country.

In Fig 4, we show, for the versions $F_{1}$ and $F_{2}$ of the renewal equation, the average error $\mathcal{S}(\tilde{t})$ over 56 consecutive days of the
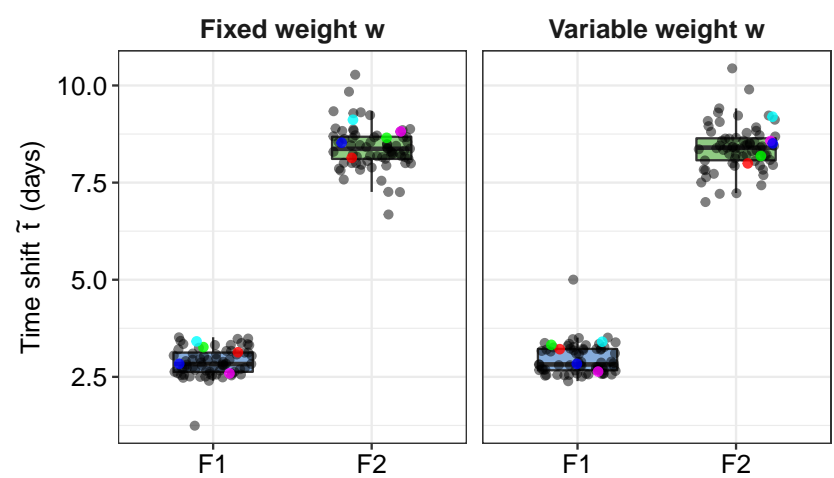

Fig. 5. Optimal time shift $\tilde{t}$ obtained by minimizing the mean error $\tilde{S}(t)$ over 56 days between the EpiEstim and the Epilnvert estimates of $R_{t}$ for each country. The time shift is as predicted by our theoretical analysis close to 3 days for $F_{1}$ and slightly above 8 days for $F_{2}$. On the left $w$ is fixed and on the right it is the optimal weight per country. France in blue, Japan in green, Peru in cyan, South Africa in magenta, USA in red.

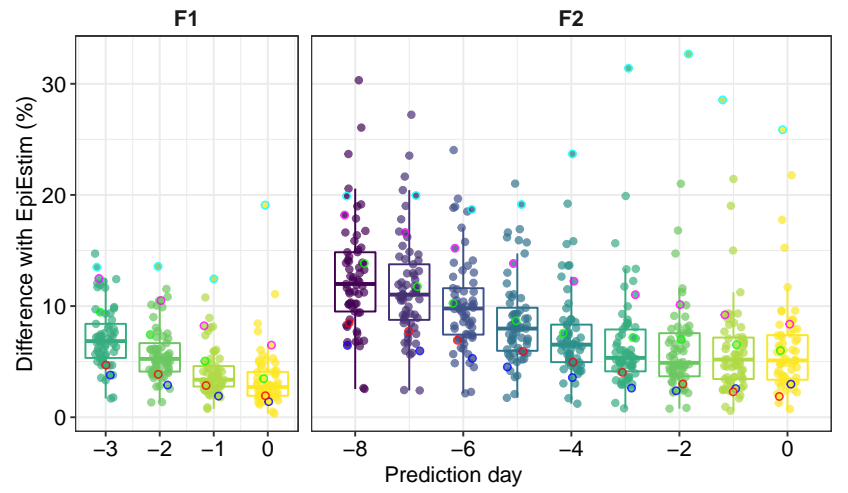

Fig. 6. Relative error between the Epilnvert and EpiEstim estimations, depending on the anticipation day. Epilnvert anticipates the value of $R_{t}$ by 0 to 3 days in the $F_{1}$ formulation and by 0 to 8 days in the $F_{2}$ formulation. Each dot represents one country. France in blue, Japan in green, Peru in black, South Africa in magenta, USA in red.

error between the EpiEstim and the EpiInvert estimates of $R_{t}$ for each country. The overall average error is $2.9 \% \pm 1.7 \%$ for $F_{1}$ and $3.6 \% \pm 1.9 \%$ for $F_{2}$. As is apparent by comparing the box plots on the left and right, the increase of the error $\mathcal{S}(\tilde{t})$ was insignificant when fixing $w$ for all countries ("fixed weight") instead of optimizing jointly on $w$ and $\tilde{t}$ for all countries ("variable weight"). In all experiments, we therefore fixed the value of $w$ to its median for all countries namely $w=5$ for $F \equiv F_{1}$, and $w=5.5$ for $F \equiv F_{2}$. Once fixed, we optimized again $\mathcal{S}(\tilde{t})$ with respect to $\tilde{t}$.

In the box plot of Fig. 5 we show, for the versions $F_{1}$ and $F_{2}$ of the renewal equation, the optimal time shift $\tilde{t}$ obtained by minimizing the mean error $\tilde{S}(t)$ over 56 days between the EpiEstim and the EpiInvert estimates of $R_{t}$ for each country. As is apparent by comparing the box plots on the left and right, there is almost no change on $\tilde{t}$ when fixing $w$ for all countries ("fixed weight") instead of optimizing jointly on $w$ and $\tilde{t}$ for all countries. We obtain respectively $\tilde{t}=2.96 \pm 0.42$ for variable $w$ and $\tilde{t}=2.86 \pm 0.43$ for $F_{1}$ with fixed $w$, and similarly for $F_{2}: \tilde{t}=8.33 \pm 0.55$ and $\tilde{t}=8.38 \pm 0.52$.

As shown in Fig. 4, the agreement between $R_{t}$ and $R_{t}^{i}$ shifted back by the optimal delay $\tilde{t}$ is overwhelming. Indeed, for $F \equiv F_{1}$, we obtain that the median of their relative difference $\mathcal{S}(\tilde{t})$ is just $2.43 \%$. For $F \equiv F_{2}$, it is $3.3 \%$. The median of the 
F1

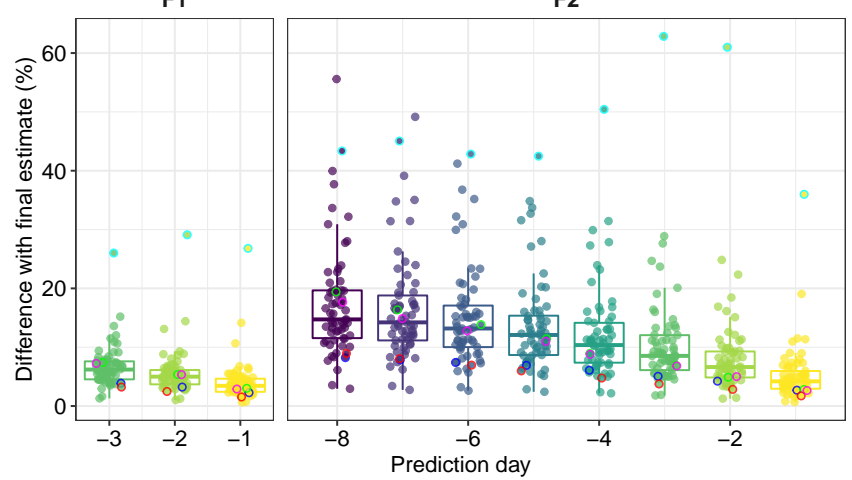

Fig. 7. Internal relative error between the Epilnvert estimations depending on the anticipation day. Each dot represents one country. The mean difference for each prediction day is marked by a horizontal bar. The standard deviation of the relative error is half the height of each box. France in blue, Japan in green, Peru in black, South Africa in magenta, USA in red.

shift $\tilde{t}$ is given by 2.89 (for $F \equiv F_{1}$ ) and 8.33 (for $F \equiv F_{2}$ ). These results are in good agreement with the discussion about the EpiEstim method we have presented above, which led to predict a time delay of 3.5 days for $F \equiv F_{1}$ and about 9 days for $F \equiv F_{2}$. The difference between the predicted time delay and the observed one therefore is 0.5 days. This is easily explained by the regularization term in Equation [7], which forces $R_{t}$ to resemble $R_{t-1}$. In summary, these experiments show that EpiEstim predicts at time $t$ a value $R_{t}$ which corresponds to day $t-8.5$ or $t-3.5$, and that EpiInvert predicts at time $t$ a value $R_{t}$ which corresponds to day $t-0.5$.

We now explore the reliability of the EpiInvert estimate, which as we saw can anticipate an estimate of $R_{t}$ by more than 8 days with respect to EpiEstim. Let us denote by $R_{t^{\prime}}(t)$ the EpiInvert estimate at time $t$ using the incidence curve up to the date $t^{\prime} \geq t$. According to the estimated shift between $R_{t}$ and $R_{t}^{i}$, for $F \equiv F_{1}, R_{t}(t-3)$ should be similar to $R_{t}^{i}$. The first estimation of $R_{t}(t-3)$ is obtained 3 days before when we compute $R_{t-3}(t-3)$.

In Fig. 6 we show a box plot of the relative error between the EpiInvert and EpiEstim estimations, depending on the anticipation day. EpiInvert anticipates the value of $R_{t}$ by 0 to 3 days in the $F_{1}$ formulation and by 0 to 8 days in the $F_{2}$ formulation. Each dot represents one country. On the left of Fig. 6 , for $F \equiv F_{1}$, we compare for $k=-3,-2,-1,0$ the means of the relative errors $\left|R_{t+k}(t-3)-R^{i}(t)\right|$ for $t \in\left[t_{c}-T+1, t_{c}\right]$ $(T=56)$ and for the 70 countries selected as the ones with higher incidence. On the right of Fig. 6 , for $F \equiv F_{2}$, we compare, in the same way, $\left|R_{t+k}(t-8)-R^{i}(t)\right|$ for $k=-8,-7, . ., 0$. Notice that the difference between the EpiInvert and EpiEstim estimates cannot be considered as an approximation error. A good agreement is expected between both estimates but the method underlying both estimations is different. Our goal was not to approximate the EspiEstim method, but to solve the renewal equation in a more exact formulation. Nevertheless, it was important to verify that EpiInvert finds very similar values to EpiEstim on their common interval of definition. These values are predicted by EpiInvert more than 8 days in advance. As expected, this relative error grows for the early predictions. Nevertheless, for the renewal equation $F_{2}$, one observes a plateau of this error between days -4 and 0 with a mean difference of about $5.5 \%$. Even with an 8 days

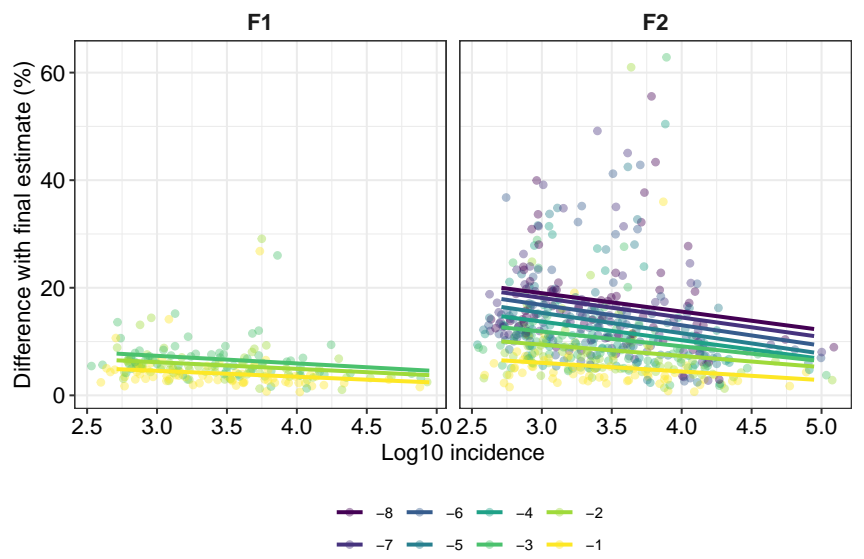

Fig. 8. Linear regression of the internal relative error between the Epilnvert estimation as a function of the mean incidence. The regression lines are clearly decreasing, which means that a higher incidence favor a better estimate of $R_{t}$.

anticipation, the average relative error on $R_{t}$ stays below $12 \%$.

Finally, we are obviously interested in the internal coherence of the EpiInvert predictions. Indeed, contrarily to EpiEstim, the EpiInvert estimate $R_{t^{\prime}}(t)$ at time $t$ evolves for $t^{\prime} \geq t$ and becomes more accurate at later dates. Fig. 7 gives a box plot of the internal relative error between the EpiInvert estimations depending on the anticipation day. On the left, for $F \equiv F_{1}$, we compare for $k=-3,-2,-1$ the means of the relative errors $\left|R_{t+k}(t-3)-R_{t}(t-3)\right|$. On the right, for $F \equiv F_{2}$, we compare, in the same way, $\left|R_{t+k}(t-8)-R_{t}(t-8)\right|$ for $k=-8, . .,-1$. Since the estimate of EpiInvert at each day evolves with the knowledge of the incidence in later days, we can see how this estimate evolves as time passes. Each dot represents one country. We see that the relative error on $R$ at a given date $t$ goes down almost linearly from $14 \%$ in an early prediction ( 8 days ahead) to $4.4 \%$ ( 1 day ahead). The robustness of the prediction is positively affected by incidence numbers.

Fig. 8 indeed shows, for each anticipation day $k=$ $-1,-2, . .$, the linear regression of the internal relative error between the EpiInvert estimations at days 0 and $k$, viewed as a function of the mean incidence of the country. These eight regression lines are clearly decreasing, which means that a higher incidence favors a better estimate of $R_{t}$. Last but not least, we evaluate the reduction obtained on the "weekend effect". Fig. 9 shows a regression plot of the reduction factor of the oscillation of $i_{t}$ obtained by applying correcting coefficients to reduce the "week-end effect". This reduction decreases from about 0.5 to less than 0.25 , the plots being ordered in increasing order of average incidence. This indicates that higher incidences lead to a more regular 7 days periodicity of the week-end effect. In https://ctim.ulpgc.es/covid19/BoxPlots/ Fig. 6 and 7 are presented in interactive mode with tooltip detailed statistics on each country.

\section{CONCLUSION}

The reproduction number $R_{t}$ can be estimated by solving a renewal equation linking $R_{t}, i_{t}$ and $\Phi_{s}$. We considered the formulations of the renewal equation providing the named instantaneous reproduction number $\left(F \equiv F_{1}\right)$ and the named 


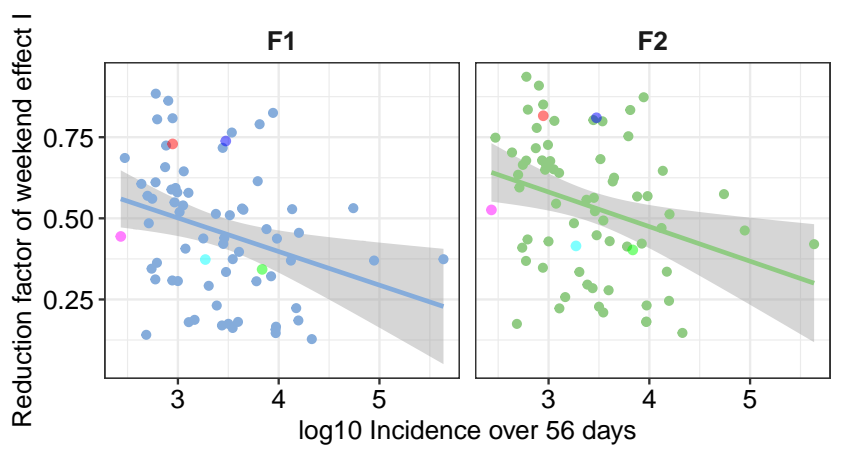

Fig. 9. Reduction factor $\mathcal{I}$ (see [10]) obtained by applying correcting coefficients to reduce the "weed end effect". This reduction decreases from about 0.5 to less than 0.25 . The plots are ordered in increasing order of average incidence.

effective reproduction number $\left(F \equiv F_{2}\right)$. The daily incidence data $i_{t}$ recorded by health administrations show a strong nonPoisson quasi-periodic behavior. In order to get an estimate of $R_{t}$ we introduced a classic regularity constraint on $R_{t}$ and we corrected the weekly periodic bias observed in the incidence curve $i_{t}$ by a simple variational formulation. Our proposed variational model, EpiInvert, also computes an empirical confidence interval. In contrast to former methods, EpiInvert can use serial intervals with distributions containing negative days (as it is the case for the COVID-19). Thus, it avoids an artificial truncation of the distribution. EpiInvert shows excellent agreement with EpiEstim. Its main improvement is to anticipate by several days the estimate of $R_{t}$ : about 3 days for the $F_{1}$ formulation of the renewal equation, and more than 8 days for its $F_{2}$ formulation. This last fact is extremely relevant, given that the control of social distancing policies requires a timely estimate of $R_{t}$.

1. P Rodpothong, P Auewarakul, Viral evolution and transmission effectiveness. World J. Virol. 1, 131 (2012).

2. X He, et al., Temporal dynamics in viral shedding and transmissibility of covid-19. Nat. medicine 26, 672-675 (2020).

3. P Ashcroft, et al., Covid-19 infectivity profile correction. arXiv preprint arXiv:2007.06602 (2020).

4. J Wallinga, $P$ Teunis, Different epidemic curves for severe acute respiratory syndrome reveal similar impacts of control measures. Am. J. epidemiology 160, 509-516 (2004).

5. A Cori, NM Ferguson, C Fraser, S Cauchemez, A new framework and software to estimate time-varying reproduction numbers during epidemics. Am. journal epidemiology 178, 15051512 (2013).

6. AJ Lotka, Relation between birth rates and death rates. Science 26, 21-22 (1907).

7. H Nishiura, Time variations in the transmissibility of pandemic influenza in Prussia, Germany, from 1918-19. Theor. Biol. Med. Model. 4, 20 (2007).

8. H Nishiura, G Chowell, The Effective Reproduction Number as a Prelude to Statistical Estimation of Time-Dependent Epidemic Trends, eds. G Chowell, JM Hyman, LMA Bettencourt, C Castillo-Chavez. (Springer Netherlands, Dordrecht), pp. 103-121 (2009).

9. K Gostic, et al., Practical considerations for measuring the effective reproductive number, Rt. MedRxiv (2020).

10. KM Gostic, et al., Practical considerations for measuring the effective reproductive number, $r$ t. PLoS computational biology 16, e1008409 (2020).

11. R Thompson, et al., Improved inference of time-varying reproduction numbers during infectious disease outbreaks. Epidemics 29, 100356 (2019).

12. QH Liu, et al., Measurability of the epidemic reproduction number in data-driven contact networks. Proc. Natl. Acad. Sci. 115, 12680-12685 (2018)

13. T Obadia, R Haneef, PY Boëlle, The r0 package: a toolbox to estimate reproduction numbers for epidemic outbreaks. BMC medical informatics decision making 12, 147 (2012).

14. TZ Boulmezaoud, L Alvarez, M Colom, JM Morel, A Daily Measure of the SARS-CoV-2 Effective Reproduction Number for all Countries. Image Processing On Line 10, 191-210 (2020) https://doi.org/10.5201/ipol.2020.304.

15. S Ma, et al., Epidemiological parameters of coronavirus disease 2019: a pooled analysis of publicly reported individual data of 1155 cases from seven countries. Medrxiv (2020).

16. J Demongeot, K Oshinubi, $\mathrm{H}$ Seligmann, $\mathrm{F}$ Thuderoz, Estimation of daily reproduction rates in covid-19 outbreak. medRxiv (2021).

17. AN Tikhonov, VY Arsenin, Solutions of ill-posed problems. New York 1, 30 (1977).

18. M Benning, M Burger, Modern regularization methods for inverse problems. Acta Numer. 27, 1-111 (2018).
19. Z Du, et al., The serial interval of COVID-19 from publicly reported confirmed cases. medRxiv (2020).

20. H Nishiura, NM Linton, AR Akhmetzhanov, Serial interval of novel coronavirus (COVID-19) infections. Int. journal infectious diseases (2020).

21. L Alvarez, Comparative analysis of the first wave of the COVID-19 pandemic in South Korea, Italy, Spain, France, Germany, the United Kingdom, the USA and the New-York state. MedRxiv (2020). 


\section{Supporting Information}

In this section we describe and analyze the EpiEstim method and its parameters (Section A). We prove in Section B that the Wallinga-Teunis method is actually computing $R_{t}$ by the $F_{1}$ form of the renewal equation. Section $C$ presents implementation details of EpiInvert. Section D makes a case study of Cuba, France, Spain and the USA. Section E contains a thorough presentation of 86 results for a collection of countries and US states in alphabetic order.

A. The EpiEstim method. One of the most widely used methods to estimate the instantaneous reproduction number is the EpiEstim method proposed by Cori et al. (5). In what follows, we will denote by $R_{t}^{i}$ the EpiEstim estimation. The authors show that if $i_{t}$ follows a Poisson distribution with expectation $\lambda=\mathbf{E}\left[i_{t}\right]=R_{t}^{i} \sum_{s=1}^{t} i_{t-s} \Phi_{s}$ and $R_{t}^{i}$ is assumed to follow a gamma prior distribution $\Gamma(a, b)$, then the following analytical expression can be obtained for the posterior distribution of $R_{t}^{i}$ :

$$
R_{t, \tau}^{i}=\frac{a+\sum_{s=t-\tau+1}^{t} i_{s}}{b^{-1}+\sum_{s=t-\tau+1}^{t} \sum_{k=1}^{f} i_{s-k} \Phi_{k}},
$$

where $R_{t}^{i}$ is assumed to be locally constant in a time window of size $\tau$ ending at time $t$. However, $i_{t}$ does not follow a Poisson distribution as its local variance in most states much higher than its mean, being dominated by the weekend effect. In this method, implemented in the EpiEstim $\mathrm{R}$ package, a regularization of the estimation is introduced by assuming that $R_{t}^{i}$ is constant in a time window of size $\tau$ ending at time $t$. We found that the parameters $a$ and $b$ of the prior Gamma distribution $\Gamma(a, b)$, have very little influence on the current estimation of $R_{t}^{i}$. Cori et al. in (5) proposed to use $a=1$ and $b=5$. Taking into account the magnitude of the current number of daily cases in countries affected by Covid-19, the contribution of $a$ and $b$ to the expression [A] can be neglected. As shown in (14), assuming that the mean $a b$ of the prior Gamma distribution $\Gamma(a, b)$ satisfies

$$
a b=\frac{\sum_{s=t-\tau+1}^{t} i_{s}}{\sum_{s=t-\tau+1}^{t} \sum_{k=1}^{f} i_{s-k} \Phi_{k}},
$$

equation $[\mathrm{A}]$ becomes

$$
R_{t, \tau}^{i}=\frac{\bar{i}_{t, \tau}}{\sum_{k=1}^{f} \bar{i}_{t-k, \tau} \Phi_{k}}
$$

which corresponds to the usual $R_{t}^{i}$ estimate obtained directly from equation [2] applied to $\bar{i}_{t}$, where $\bar{i}_{t}$ is the average of $i_{t}$ in the interval $[t-\tau, t]$. Therefore, if we remove the parameters $a$ and $b$ from the estimation of $R_{t}^{i}$, the main difference between the EpiEstim estimation and the one proposed here for $F \equiv F_{1}$ is that in EpiEstim, a serial interval with non-positive values is not allowed and that the regularity is forced by a backward seven day average of the incidence curve. This is replaced by a regularity term in the proposed variational formulation. Notice that due to the backward averaging of the incidence curve, we can expect a time shift between both estimations.

B. The Wallinga and Teunis computation of $R_{t}$. The WallingaTeunis (4) method is also implemented in the EpiEstim package and widely considered as a reliable method to compute $R_{t}$ retrospectively (10). Its formulas to estimate $R_{t}$ at time $t$ require the knowledge of $i_{t}$ for $t=0, \cdots, t+f$. Starting from the original definitions of the authors, we give a mathematical proof that their method is actually computing $R_{t}$ by the $F_{1}$ form of the renewal equation. The method is based on the following estimation of the "relative likelihood, $p_{k, l}$, that a case $k$ has been infected by case $l "$,

$$
p_{k, l}=\frac{\Phi\left(t_{k}-t_{l}\right)}{\sum_{m=1, m \neq k}^{n} \Phi\left(t_{k}-t_{m}\right)}
$$

where $n$ represents the reported cases and $t_{k}$ is the time of infection for the case $k$. Wallinga and Teunis define the case reproduction number by

$$
R_{l}=\sum_{k} p_{k, l}
$$

Since $R_{l}$ only depends on the time of infection $t_{l}$, it is actually an estimation of the reproduction number at time $t=t_{l}$, so the Wallinga and Teunis estimate, $R_{t}^{W T}$, of the reproduction number can be expressed as:

$$
R^{W T}(t)=\sum_{k} \frac{\Phi\left(t_{k}-t\right)}{\sum_{m=1, m \neq k}^{n} \Phi\left(t_{k}-t_{m}\right)}
$$

It remains to establish a relation of $R^{W T}(t)$ with the solution $\tilde{R}_{t}$ obtained by the renewal equation with $F \equiv F_{1}$,

$$
\tilde{R}_{t}=\frac{i_{t}}{\sum_{s>0} i_{t-s} \Phi_{s}} .
$$

Grouping in the sum in [E] the cases $k$ such that $t_{k}=\bar{t}$ and taking into account that there are $i_{\bar{t}}$ such cases, $R_{t}^{W T}$ can be rewritten as

$$
R_{t}^{W T}=\sum_{\bar{t}} \frac{\Phi(\bar{t}-t) i_{\bar{t}}}{\sum_{s>0} i_{\bar{t}-s} \Phi_{s}}=\sum_{\bar{t}} \Phi(\bar{t}-t) \tilde{R}_{\bar{t}} .
$$

We can therefore interpret $R_{t}^{W T}$ as the forward convolution of the initial estimate $\tilde{R}_{t}$ with the kernel given by $\Phi_{s}$. On the other hand, as explained above, the EpiEstim estimate $R_{t}^{i}$ can be interpreted (if we neglect the parameters $a$ and $b$ of the Gamma distribution) as the application of Equation $[\mathrm{F}]$ to the incidence curve filtered by sliding average on $[t-\tau+1, t]$. In conclusion the Cori et al. and the Wallinga and Teunis methods use the renewal equation $F \equiv F_{1}$. Note, however, that the Wallinga and Teunis method computes the reproduction number only retrospectively. Indeed, the computation of $R_{t}^{W T}$ requires the values of $i_{\tilde{t}}$ for any $\tilde{t}>t$ such that $\Phi(\tilde{t}-t)>0$. This fact was observed in Cori et al.: (in the WT approach), "estimates are right censored, because the estimate of $R$ at time $t$ requires incidence data from times later than $t$."

\section{Implementation details of Epilnvert.}

Alternate minimization of the energy [7]. To minimize the energy [7], we use an alternate minimization algorithm with respect to $R_{t}$ and $\mathbf{q}$. Indeed, if $\mathbf{q}$ is fixed, then the optimization of the energy [7] with respect to $R_{t}$ leads to a linear system of equations that is easily solved. In what follows, we will denote by $R(t, i, \mathbf{q})$ the result of this minimization. On the other hand, when $R_{t}$ is fixed, the minimization of [7] with respect 
to $\mathbf{q}$ also leads to a linear system of equations. The constraint [8] is expressed as an additional linear equation,

$$
\mu_{0} q_{0}+\mu_{1} q_{1}+\mu_{2} q_{2}+\mu_{3} q_{3}+\mu_{4} q_{4}+\mu_{5} q_{5}+\mu_{6} q_{6}=\sum_{t=t_{c}-T+1}^{t_{c}} i_{t},[\mathrm{H}]
$$

where $\mu_{k}=\sum_{t=t_{c}-T+1}^{k+7 t \leq t_{c}} i_{k+7 t}$. This linear constraint is easily included in the minimization procedure using, for instance, Lagrange multipliers. So $\mathbf{q}$ is computed as the unique solution of the associated linear system. In what follows we will denote by $\mathbf{q}(R)$ the result of this minimization. Let us denote by $R_{t}^{n}$ and $\mathbf{q}^{n}$ the estimation of $R_{t}$ and $\mathbf{q}$ in the iteration $n$ of the alternate minimization algorithm. We also denote by $i_{t}^{n}=$ $i_{t} \cdot q_{t \% 7}^{n}$ the filtered incidence curve at iteration $n$. We initialize $n=0, i^{0} \equiv i, \mathbf{q}^{0} \equiv 1$ and we compute $R_{t}^{0}=R\left(t, i^{0}, \mathbf{q}^{0}\right)$ as the minimizer of the energy [7] with respect to $R_{t}$ for $\mathbf{q} \equiv \mathbf{q}^{0}$.

The whole method is summarized in Algorithm 1, where the maximum number of iterations is fixed to MaxIter $=100$.

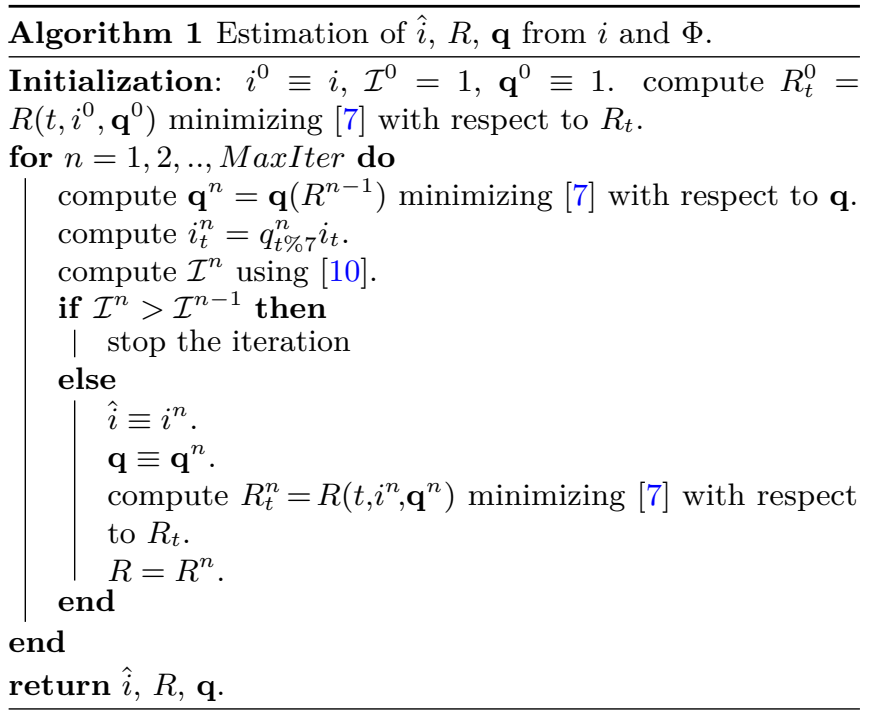

Initial boundary condition, for $t=0$. The evaluation of $F_{2}(i, R, \Phi, t)$ requires values of $R_{t}$ and $i_{t}$ beyond the interval $\left[0, t_{c}\right]$. Given the boundary conditions established, we assume that $R_{t}=R 0$ for $t<0$ and $R_{t}=R_{t_{c}}$ for $t>t_{c}$. Concerning $i_{t}$, for $t<0$ we will assume, as usual, that at the beginning of the epidemic spread the virus is in free circulation and the cumulative number of infected detected $I_{t} \equiv \sum_{k=0}^{t} i_{k}$ follows an exponential growth for $t<0$, that is $I_{t}=I_{0} e^{a t}$, where $a$ represents the initial exponential growth rate of $I_{t}$ at the beginning of the infection spread. We now naturally estimate $a$ by

$$
a=\operatorname{median}\left(\left\{\log \left(\frac{I_{t+1}}{I_{t}}\right): t=0, . ., 14\right\}\right) .
$$

If we assume that $I_{t}=I_{0} e^{a t}$ follows initially an exponential growth and that $R_{t}=R 0$ is initially constant, then we can compute $R 0$ from the exponential growth $a$ and the renewal equation taking into account that

$$
i_{0}=I_{0}\left(1-e^{-a}\right)=I_{0} R 0 \sum_{k=f_{0}}^{f}\left(e^{-k a}-e^{-(k+1) a}\right) \Phi_{k} .
$$

Hence, we can compute an approximation of $R 0$ as

$$
R 0=\frac{1-e^{-a}}{\sum_{k=f_{0}}^{f}\left(e^{-k a}-e^{-(k+1) a}\right) \Phi_{k}} .
$$

Note that this estimation strongly depends on the serial interval used. For instance, if we assume that $a=0.250737$ (the exponential growth rate obtained in (21) when the coronavirus is in free circulation), we obtain that $R 0=2.700635$ for the Nishiura et al. serial interval, $R 0=3.084528$ for the Ma et al. serial interval and $R 0=1.839132$ for the Du et al. serial interval.

Boundary condition for $\left[t>t_{c}\right]$. The proposed inversion model provides an estimation of $R_{t}$ up to the current day $t_{c}$. An obvious objection is that if $f_{0}<0$, the functional [7] involves a few future values of $R_{t}$ and $i_{t}$ for $t_{c} \leq t \leq t_{c}-f_{0}$. These values are unknown at present time $t_{c}$. We use a basic linear regression to extrapolate the values of $i_{t}$ beyond $t_{c}$. To compute the regression line $\left(i=m_{7} \cdot t+n_{7}\right)$ we use the last seven values of $i_{t}$. In summary, the extension of $i_{t}$ beyond the observed interval $\left[0, t_{c}\right]$ is defined by

$$
i_{t}=\left\{\begin{array}{ccc}
I_{0} e^{a t}-I_{0} e^{a(t-1)} & \text { if } & t<0 \\
m_{7} \cdot t+n_{7} & \text { if } & t>t_{c} .
\end{array}\right.
$$

The above defined boundary conditions has a very minor influence in the final estimation of $R_{t}$ in the last days when minimizing [7]. Indeed, the extension of $i_{t}$ for $t<0$ is only relevant at the beginning of the epidemic spread. On the other hand, the extension of $i_{t}$ for $t>t_{c}$ is only required when the serial interval has negative values. For instance, to evaluate the renewal equation in the energy at the current time $t_{c}$ using this approach for $F \equiv F_{2}$ we use the expression

$$
i_{t_{c}}=\sum_{s=0}^{f} i_{t_{c}-s} R_{t_{c}-s} \Phi_{s}+\sum_{s=f_{0}}^{-1} i_{t_{c}-s} R_{t_{c}} \Phi_{s}
$$

and the extension of $i_{t}$ for $t>t_{c}$ is only used in the last term of the above expression where the values of $\Phi_{s}$ are usually very small. Hence the influence of this extension procedure for $i_{t}$ is also almost negligible. To confirm this claim, we compared, using the shifted log-normal approximation of the serial interval proposed by Ma et al., the estimate of $R_{t_{c}}$ using the extrapolation based on a linear regression of the last 7 days, with the basic extrapolation given by $i_{t}=i_{t_{c}}$ for $t>t_{c}$. Computing the absolute value of the difference of both estimates for 81 countries we obtain that the quartiles of such distribution of values are $Q_{0}=6.6 \cdot 10^{-6}, Q_{1}=1.3 \cdot 10^{-4}$, $Q_{2}=3.1 \cdot 10^{-4}, Q_{3}=5.7 \cdot 10^{-4}$ and $Q_{4}=4.9 \cdot 10^{-3}$. We conclude that extrapolation of $i_{t}$ beyond $t_{c}$ is a valid strategy to estimate $R_{t}$ up to $t=t_{c}$.

Pre-processing the incidence curve. Some countries do not provide data on holidays or weekends and only provide the cumulative total of cases on the next working day. To avoid the strong discontinuity in the data sequence produced by the lack of data, we automatically divide the case numbers of the first non-missing day, between the number of days affected. We do not allow negative numbers in the incidence curve. By default, we replace by zero any negative value of the incidence curve. 
D. Case studies: Cuba, France, Spain, USA and World . The country data about the registered daily infected are taken from https://ourworldindata.org. In the particular cases of France, Spain and Germany we use the official data reported by the countries. For the US states, the data are obtained from the New York Times report available at https://raw.githubusercontent.com/nytimes/covid-19-data/ master/us-states.csv.

In Fig. S1 we show the charts obtained for the world population with $F \equiv F_{1}$ and $F \equiv F_{2}$. Table S1 contains a summary of the values computed for each experiment. To compute the EpiEstim estimation $R_{t}^{i}$, we used $\tau=7$, that is, we assumed that $R_{t}$ is constant in $[t-7, t]$. As proposed by Cori et al. in (5) we used $a=1$ and $b=5$ for the parameters of the $\Gamma(a, b)$ prior distribution for $R_{t}$. Yet, as explained above, these values could be neglected in the EpiEstim estimation, given the magnitude of the incidence data in these regions.

The total world population shows a clear weekly periodic bias. The correction of this bias works quite well, as the RMSE reduction reaches $\mathcal{I}=0.337$ for $F \equiv F_{1}$ and $\mathcal{I}=0.380$ for $F \equiv F_{2}$. The oscillation of the incidence curve is strongly reduced, passing from $\mathcal{V}(i)=0.115$ to $\mathcal{V}(\hat{i})=0.063$. The agreement with EpiEstim is also excellent as $\mathcal{S}(\tilde{t})=0.01$ for $F \equiv F_{1}$ and $\mathcal{S}(\tilde{t})=0.014$ for $F \equiv F_{2}$. The daily bias correction factors are similar for $F \equiv F_{1}$ and $F \equiv F_{2}$. On Sundays and Mondays the number of cases is underestimated and overestimated on Wednesdays, Thursdays and Fridays.

France also displays a clear weekly periodic bias: on Mondays the number of cases is strongly underestimated, and on Wednesdays it is strongly overestimated. The correction of the periodic bias works well, as $\mathcal{I}=0.481$ for $F \equiv F_{1}$ and $\mathcal{I}=0.513$ for $F \equiv F_{2}$. The oscillation of the incidence curve is therefore reduced, passing from $\mathcal{V}(i)=0.329$ to $\mathcal{V}(\hat{i})=0.202$. The agreement with the EpiEstim method is good, with $\mathcal{S}(\tilde{t})=0.026$ for $F \equiv F_{1}$ and $\mathcal{S}(\tilde{t})=0.025$ for $F \equiv F_{2}$.

Spain is special: it does not provide data on weekends or holidays. In that case a constant value is being assigned to $i_{t}$ in the affected days. Despite this, the correction of the weekly periodic bias works again well and yields $\mathcal{I}=0.171$ for $F \equiv F_{1}$ and $\mathcal{I}=0.290$ for $F \equiv F_{2}$. The oscillation of the incidence curve reduces from $\mathcal{V}(i)=0.135$ to $\mathcal{V}(\hat{i})=0.087$. The agreement with the EpiEstim method is good, with $\mathcal{S}(\tilde{t})=$ 0.025 for $F \equiv F_{1}$ and $\mathcal{S}(\tilde{t})=0.046$ for $F \equiv F_{2}$. Observe how the incidence curve is underestimated on Sundays, Mondays and Tuesdays, and overestimated on Thursdays, Fridays and Saturdays.

In the USA we obtain $\mathcal{I}=0.450$ for $F \equiv F_{1}$ and $\mathcal{I}=0.569$ for $F \equiv F_{2}$. The oscillation of the incidence curve is reduced from $\mathcal{V}(i)=0.130$ to $\mathcal{V}(\hat{i})=0.085$. The agreement with EpiEstim is again very good with $\mathcal{S}(\tilde{t})=0.014$ for $F \equiv F_{1}$ and $\mathcal{S}(\tilde{t})=0.023$ for $F \equiv F_{2}$. On Sundays the number of cases is underestimated, and overestimated on Fridays.

Although in general countries present a clear weekly periodic pattern in the incidence curve this is not the case for Cuba. In this country we obtain $\mathcal{I}=0.890$ for $F \equiv F_{1}$ and $\mathcal{I}=0.928$ for $F \equiv F_{2}$. The incidence curve oscillation is slightly reduced after the correction of the periodic bias. Finally, the agreement with the EpiEstim method is good, with $\mathcal{S}(\tilde{t})=0.034$ for $F \equiv F_{1}$ and $\mathcal{S}(\tilde{t})=0.041$ for $F \equiv F_{2}$.

The values of the bias correction coefficients $q_{k}$ obtained for $F \equiv F_{1}$ and $F \equiv F_{2}$ are quite similar. So it seems that the choice of the renewal equation has no significant influence on the estimation of the bias correction coefficients.

The optimal shift $\tilde{t}$ between $R_{t}$ is $R_{t}^{i}$ fits in the range obtained by a joint analysis of the 70 countries. Indeed, for $F \equiv F_{1} \tilde{t}$ ranges from 2.72 to 3.50 and for $F \equiv F_{2} \tilde{t}$ ranges from 8.00 to 9.7 .

E. Additional experiments. We can start this large set of experiments with a recent example in France showing how EpiInvert gives a valuable extension to EpiEstim. In Fig. S2 we observe a very good agreement between the EpiEstim estimate of $R(t)$ by March $26(R(t)=1.239)$ and the EpiInvert estimate 8 days in advance $(R(t)=1.221)$. But the EpiInvert estimate is more regular and it does not produce the singularity observed in the EpiEstim estimate by March 15 .

Next, for $F \equiv F_{2}$, using the data of incidence curve up to March 26, 2021, we present a collection of 64 experiments on different countries and separately 24 experiments on some US states. The regions are sorted in alphabetic order. For each experiment we show the charts and the following selection of numerical values:

1. $\mathcal{I}$ : reduction factor of the RMSE error between $i_{t}$ and $F(i, R, \Phi, t)$ before and after the correction of the weekly periodic bias defined as:

$$
\mathcal{I}=\sqrt{\frac{\sum_{t=t_{c}-T+1}^{t_{c}}\left(\hat{i}_{t}-F(\hat{i}, R, \Phi, t)\right)^{2}}{\sum_{t=t_{c}-T+1}^{t_{c}}\left(i_{t}-F(i, R 1, \Phi, t)\right)^{2}}}
$$

where $\hat{i}$ represents the incidence curve after correction and $R 1($.$) represents the initial R_{t}$ estimate without correcting the periodic bias. In the case we do not apply the correction of the periodic bias, this value does not appear in the experiment.

2. $\tilde{t}$ : optimal shift (in days) between our estimate of $R$ and the one obtained by EpiEstim.

3. $\mathcal{S}(\tilde{t})$ : RMSE between our estimate of $R$ and the one obtained by EpiEstim shifted back $\tilde{t}$ days.

4. $R_{t_{c}}^{i}$ : last available value of the EpiEstim estimate $R_{t}^{i}$.

5. $R_{t_{c}}$ : last available value of our $R_{t}$ estimate.

The default value for the regularization parameter is $w=5$ for $F \equiv F_{1}$ and $w=5.5$ for $F \equiv F_{2}$, otherwise it is explicitly written in the experiment.

In general the correction of the weekly periodic bias works quite well. We can highlight the following regions where such correction works extremely well: Germany $(\mathcal{I}=0.166)$, Croatia $(\mathcal{I}=0.174)$, Sweden $(\mathcal{I}=0.192)$, Switzerland $(\mathcal{I}=$ $0.206)$, Poland $(\mathcal{I}=0.227)$, Portugal $(\mathcal{I}=0.23)$, and Utah $(\mathcal{I}=0.292)$. On the other side, there is also a number of regions where the correction of the weekly bias does not work well as Uruguay $(\mathcal{I}=0.822)$, China $(\mathcal{I}=0.826)$, Peru $(\mathcal{I}=$ $0.83)$, Ethiopia $(\mathcal{I}=0.831)$, Indonesia $(\mathcal{I}=0.89)$, Cuba $(\mathcal{I}=0.928)$, Cyprus $(\mathcal{I}=0.94)$, Washington $(\mathcal{I}=0.816)$, New York $(\mathcal{I}=0.86)$ and Connecticut $(\mathcal{I}=0.936)$.

For some regions where the value of $\mathcal{S}(\tilde{t})$ is high, we repeat the experiment without correcting the weekly periodic bias. In general, in such cases we observe that profile of the $R_{t}$ estimate is similar in both cases and the experimental variability is lower (or similar) in the case of using the bias correction. That is the 
medRxiv preprint doi: https://doi.org/10.1101/2020.08.01.20165142; this version posted June 14, 2021. The copyright holder for this preprint (which was not certified by peer review) is the author/funder, who has granted medRxiv a license to display the preprint in perpetuity.

It is made available under a CC-BY-NC-ND 4.0 International license .
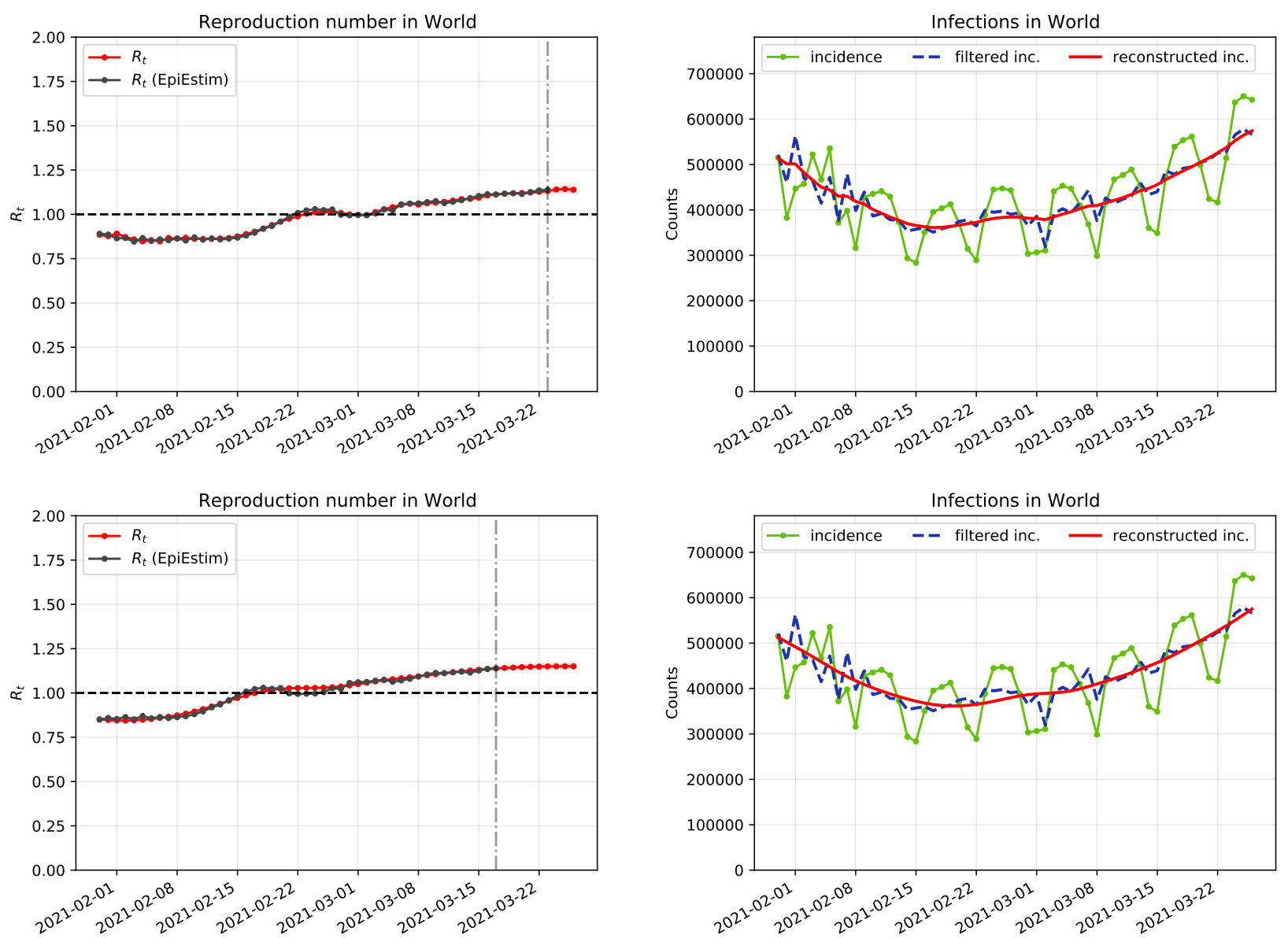

Fig. S1. Results obtained for the world population up to March 26, 2021 using: (top) $F \equiv F_{1}$ and (down) $F \equiv F_{2}$.

\begin{tabular}{|c|c|c|c|c|c|c|c|c|c|c|}
\hline & World & World & France & France & Spain & Spain & USA & USA & Cuba & Cuba \\
\hline$F$ & $F_{1}$ & $F_{2}$ & $F_{1}$ & $F_{2}$ & $F_{1}$ & $F_{2}$ & $F_{1}$ & $F_{2}$ & $F_{1}$ & $F_{2}$ \\
\hline$\tilde{t}$ & 2.72 & 8.94 & 3.50 & 9.05 & 3.38 & 9.70 & 2.72 & 8.76 & 3.09 & 8.00 \\
\hline $\mathcal{S}(\tilde{t})$ & 0.010 & 0.014 & 0.026 & 0.025 & 0.025 & 0.046 & 0.014 & 0.023 & 0.034 & 0.041 \\
\hline $\mathcal{I}$ & 0.337 & 0.380 & 0.481 & 0.513 & 0.171 & 0.290 & 0.450 & 0.569 & 0.890 & 0.928 \\
\hline$q_{1}$ & 1.011 & 1.012 & 0.931 & 0.932 & 1.263 & 1.266 & 1.008 & 1.005 & 1.005 & 1.006 \\
\hline$q_{2}$ & 1.204 & 1.204 & 1.073 & 1.078 & 1.227 & 1.208 & 1.262 & 1.250 & 0.945 & 0.945 \\
\hline$q_{3}$ & 1.260 & 1.259 & 3.201 & 3.180 & 1.177 & 1.149 & 1.095 & 1.083 & 1.049 & 1.049 \\
\hline$q_{4}$ & 1.027 & 1.026 & 1.062 & 1.062 & 1.031 & 1.009 & 1.053 & 1.057 & 0.923 & 0.921 \\
\hline$q_{5}$ & 0.887 & 0.888 & 0.698 & 0.691 & 0.857 & 0.858 & 0.925 & 0.936 & 1.025 & 1.025 \\
\hline$q_{6}$ & 0.888 & 0.889 & 0.889 & 0.886 & 0.802 & 0.817 & 0.909 & 0.915 & 1.037 & 1.037 \\
\hline$q_{7}$ & 0.881 & 0.881 & 0.944 & 0.955 & 0.834 & 0.863 & 0.867 & 0.869 & 1.026 & 1.027 \\
\hline
\end{tabular}

Table S1. Numerical results obtained by Epilnvert for the world population, France, Spain, the USA and Cuba using the data up to March 26 , 2021 and the renewal equations $F=F_{1}$ and $F=F_{2}$. 
medRxiv preprint doi: https://doi.org/10.1101/2020.08.01.20165142; this version posted June 14, 2021. The copyright holder for this preprint (which was not certified by peer review) is the author/funder, who has granted medRxiv a license to display the preprint in perpetuity.

\section{It is made available under a CC-BY-NC-ND 4.0 International license .}
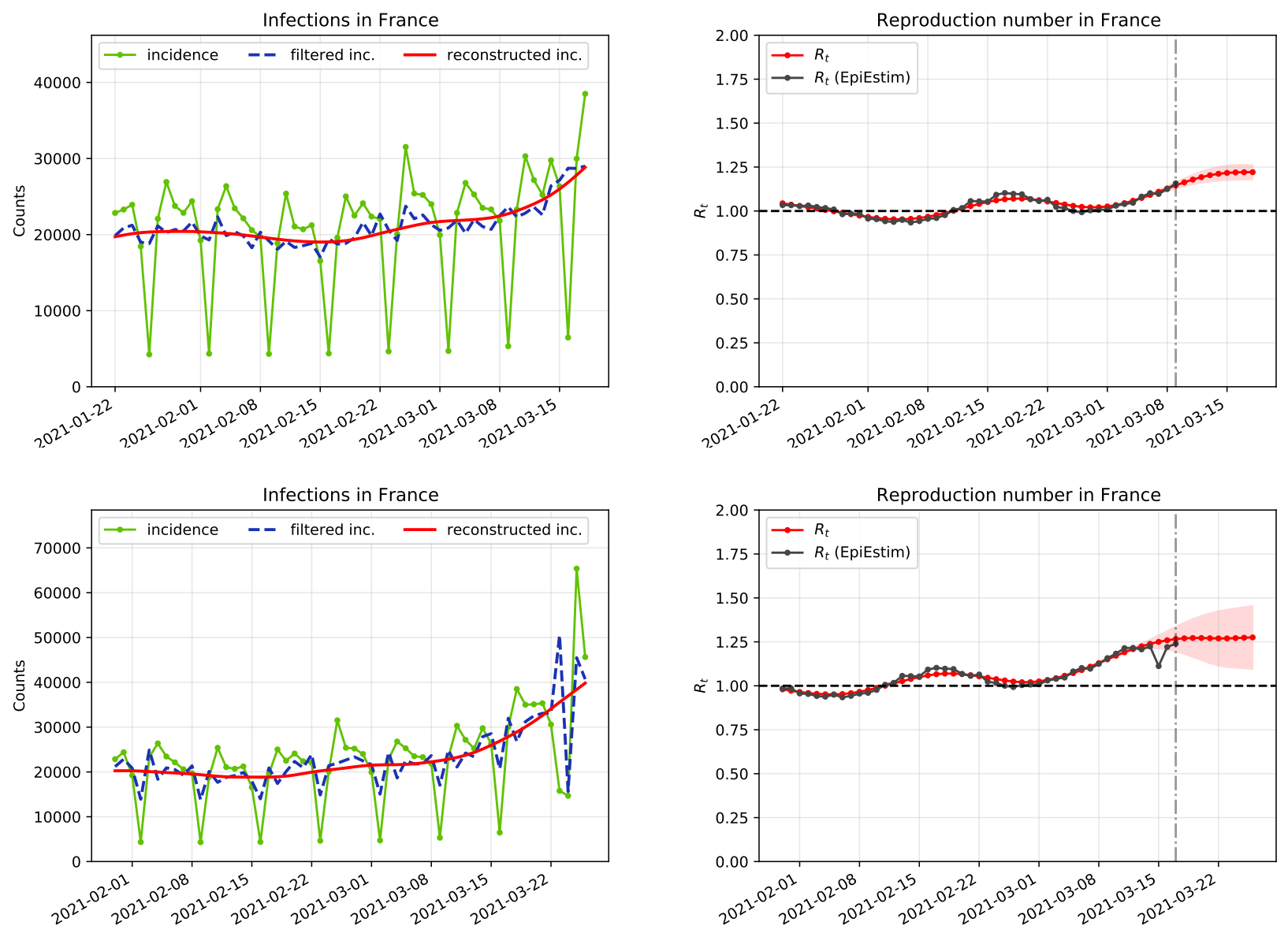

Fig. S2. Comparison of the EpiEstim estimate of $R(t)$ in France by March $26(R(t)=1.239)$ and the Epilnvert estimate 8 days in advance $(R(t)=1.221)$. Notice the singularity observed in the EpiEstim estimate by March 15 . 
medRxiv preprint doi: https://doi.org/10.1101/2020.08.01.20165142; this version posted June 14, 2021. The copyright holder for this preprint

(which was not certified by peer review) is the author/funder, who has granted medRxiv a license to display the preprint in perpetuity.

It is made available under a CC-BY-NC-ND 4.0 International license .

case of Canada, China, Cuba, Cyprus, Ethiopia, Peru, New York or Washington. In the case of Denmark, both estimations of $R_{t}$ are quite different and the experimental variability are very high due to some high oscillations of the incidence curve in the last days of the sequence.

A very special case is Kansas. As can be observed in Fig. $\mathrm{S} 21$, although the correction of the weekly periodic bias is not bad $(\mathcal{I}=0.595)$ the obtained $R_{t}$ estimate is very inaccurate. The reason is that the incidence curve of Kansas is extremely oscillating $(\mathcal{V}(i)=1.728$ (notice that in the USA $\mathcal{V}(i)=0.130)$ ) but the oscillations are not 7-day periodic and the correction of the weekly periodic bias produces high distortions of the incidence curve when we approach the last day of the sequence. In this very particular case it is clearly better to do not use the correction of the weekly bias. Moreover, due to the extremely oscillating behaviour of the incidence curve, as shown in the experiments of Fig. S21 a high value of the regularization parameter $(w=40)$ is required in order to properly regularize the estimate of $R_{t}$.

Concerning the agreement with EpiEstim we observe that countries with small oscillations in the incidence curve like Iran $(\mathcal{V}(i)=0.023)$ or Russia $(\mathcal{V}(i)=0.031)$ show excellent agreement with EspiEstim $(\mathcal{S}(\tilde{t})=0.006$ for Iran and $\mathcal{S}(\tilde{t})=0.01$ for Russia). On the other hand, countries with small number of cases like China have no good agreement with EpiEstim $(\mathcal{S}(\tilde{t})=0.142)$ with the default value of the regularization parameter $w$. In such cases our $R_{t}$ estimate is much more regular than the one of EpiEstim. 
medRxiv preprint doi: https://doi.org/10.1101/2020.08.01.20165142; this version posted June 14, 2021. The copyright holder for this preprint (which was not certified by peer review) is the author/funder, who has granted medRxiv a license to display the preprint in perpetuity.

It is made available under a CC-BY-NC-ND 4.0 International license .
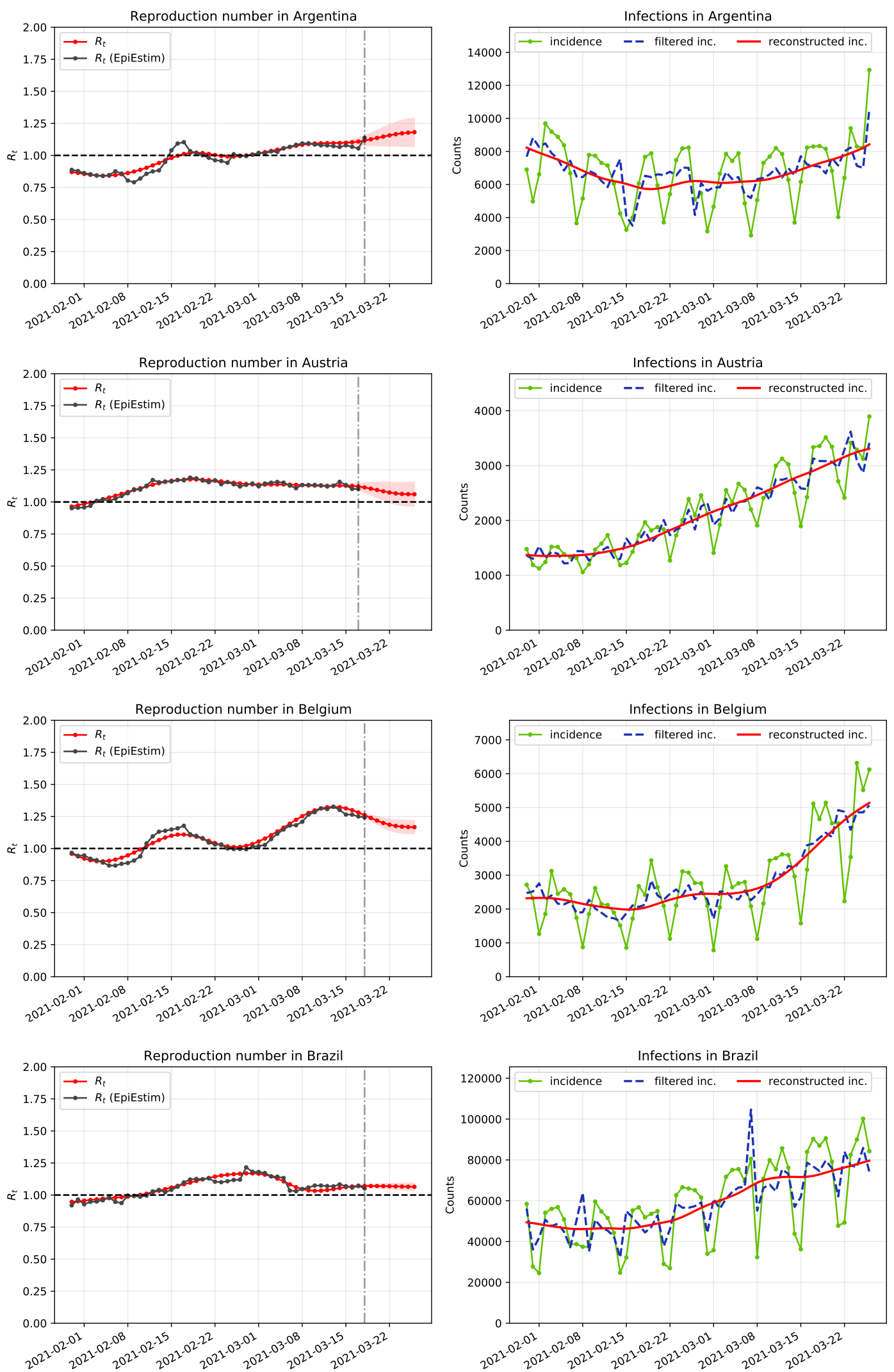

Fig. S3. From top to down: $\operatorname{Argentina}\left(\mathcal{I}=0.451, \tilde{t}=8.11, \mathcal{S}(\tilde{t})=0.033, R^{i}\left(t_{c}\right)=1.137, R\left(t_{c}\right)=1.181\right)$, Austria $(\mathcal{I}=0.464, \tilde{t}=9.37, \mathcal{S}(\tilde{t})=0.014$, $\left.R^{i}\left(t_{c}\right)=1.101, R\left(t_{c}\right)=1.060\right)$, Belgium $\left(\mathcal{I}=0.293, \tilde{t}=8.49, \mathcal{S}(\tilde{t})=0.031, R^{i}\left(t_{c}\right)=1.242, R\left(t_{c}\right)=1.166\right)$ and Brazil $(\mathcal{I}=0.560, \tilde{t}=8.21, \mathcal{S}(\tilde{t})=0.027$ $\left.R^{i}\left(t_{c}\right)=1.051, R\left(t_{c}\right)=1.064\right)$. 
medRxiv preprint doi: https://doi.org/10.1101/2020.08.01.20165142; this version posted June 14, 2021. The copyright holder for this preprint (which was not certified by peer review) is the author/funder, who has granted medRxiv a license to display the preprint in perpetuity.

It is made available under a CC-BY-NC-ND 4.0 International license .
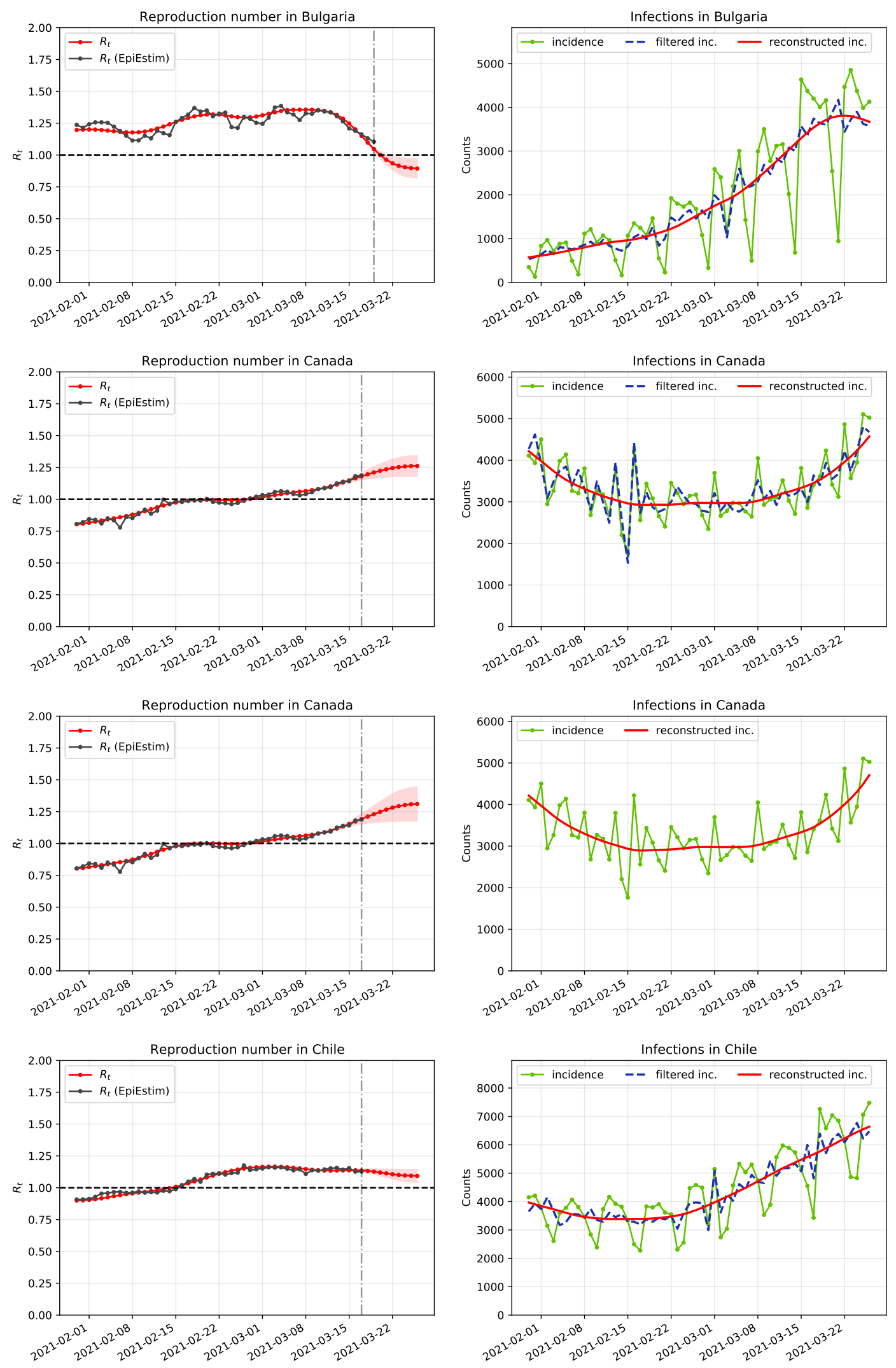

Fig. S4. From top to down: Bulgaria $\left(\mathcal{I}=0.245, \tilde{t}=7.23, \mathcal{S}(\tilde{t})=0.041, R^{i}\left(t_{c}\right)=1.105, R\left(t_{c}\right)=0.894\right)$, Canada $(\mathcal{I}=0.780, \tilde{t}=9.10, \mathcal{S}(\tilde{t})=0.019$, $\left.R^{i}\left(t_{c}\right)=1.187, R\left(t_{c}\right)=1.262\right)$, Canada $\left(\tilde{t}=9.07, \mathcal{S}(\tilde{t})=0.019, R^{i}\left(t_{c}\right)=1.187, R\left(t_{c}\right)=1.311\right)$ and Chile $(\mathcal{I}=0.385, \tilde{t}=8.95, \mathcal{S}(\tilde{t})=0.017$, $\left.R^{i}\left(t_{c}\right)=1.127, R\left(t_{c}\right)=1.093\right)$. 
medRxiv preprint doi: https://doi.org/10.1101/2020.08.01.20165142; this version posted June 14, 2021. The copyright holder for this preprint (which was not certified by peer review) is the author/funder, who has granted medRxiv a license to display the preprint in perpetuity.

It is made available under a CC-BY-NC-ND 4.0 International license .
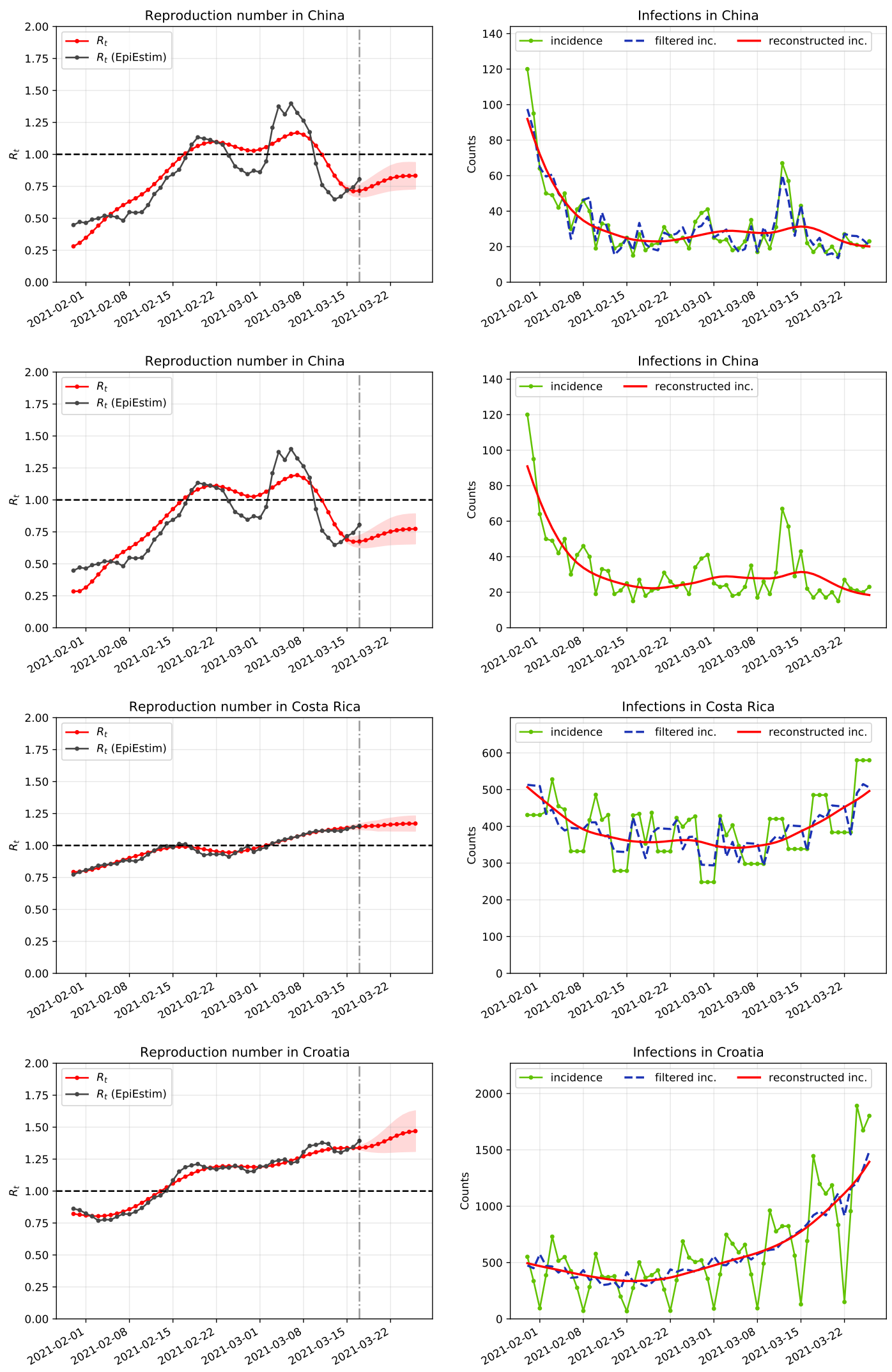

Fig. S5. From top to down: China $\left(\mathcal{I}=0.826, \tilde{t}=9.30, \mathcal{S}(\tilde{t})=0.142, R^{i}\left(t_{c}\right)=0.805, R\left(t_{c}\right)=0.833\right)$, China $\left(\tilde{t}=9.11, \mathcal{S}(\tilde{t})=0.131, R^{i}\left(t_{c}\right)=0.805\right.$, $\left.R\left(t_{c}\right)=0.773\right)$, Costa Rica $\left(\mathcal{I}=0.499, \tilde{t}=8.97, \mathcal{S}(\tilde{t})=0.018, R^{i}\left(t_{c}\right)=1.154, R\left(t_{c}\right)=1.172\right)$ and Croatia $(\mathcal{I}=0.174, \tilde{t}=8.88, \mathcal{S}(\tilde{t})=0.033$, $\left.R^{i}\left(t_{c}\right)=1.393, R\left(t_{c}\right)=1.469\right)$. 
medRxiv preprint doi: https://doi.org/10.1101/2020.08.01.20165142; this version posted June 14, 2021. The copyright holder for this preprint (which was not certified by peer review) is the author/funder, who has granted medRxiv a license to display the preprint in perpetuity.

It is made available under a CC-BY-NC-ND 4.0 International license .
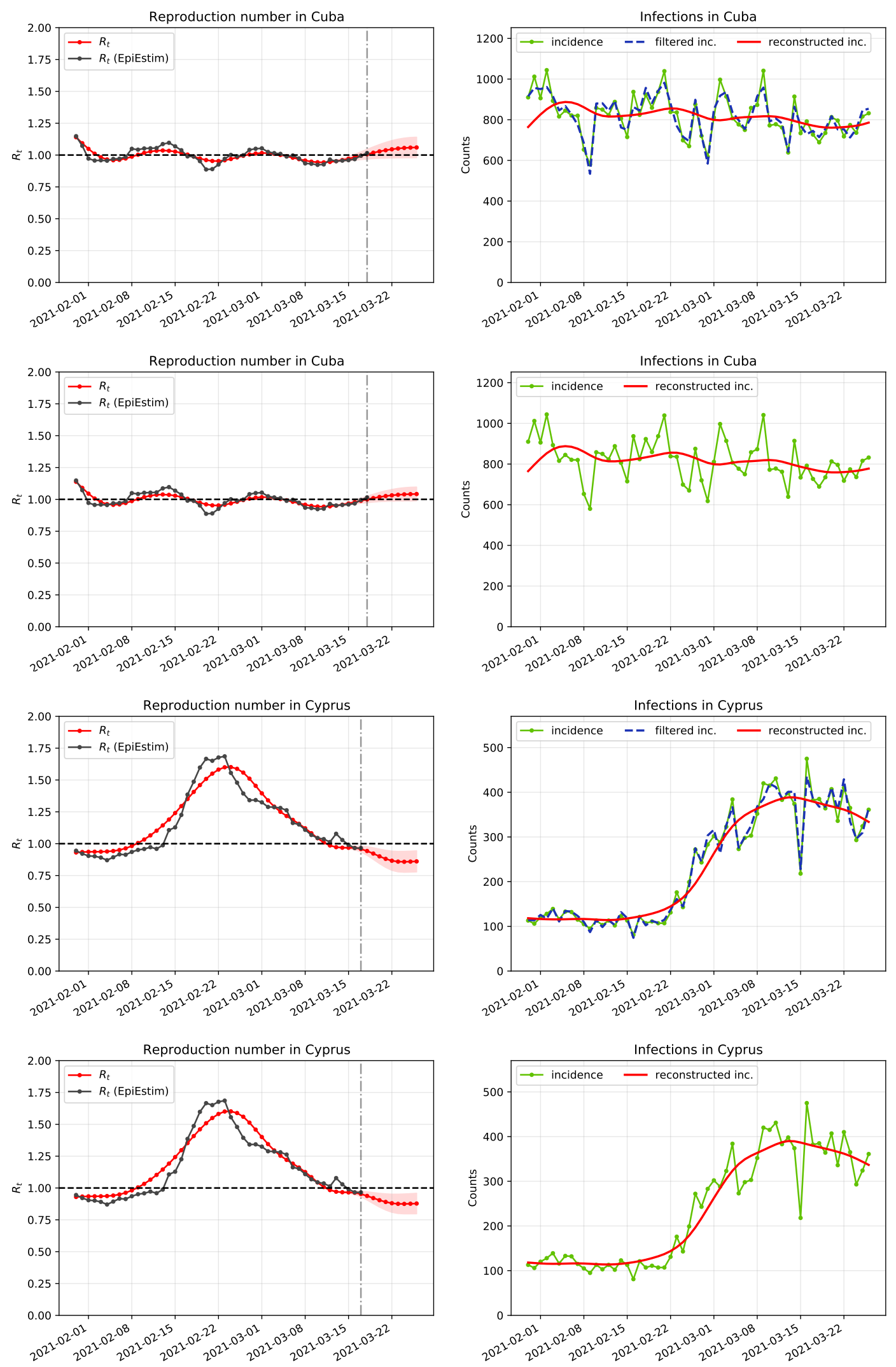

Fig. S6. From top to down: Cuba $\left(\mathcal{I}=0.928, \tilde{t}=8.00, \mathcal{S}(\tilde{t})=0.041, R^{i}\left(t_{c}\right)=1.016, R\left(t_{c}\right)=1.060\right)$, Cuba $\left(\tilde{t}=8.00, \mathcal{S}(\tilde{t})=0.040, R^{i}\left(t_{c}\right)=1.016\right.$, $\left.R\left(t_{c}\right)=1.042\right)$, Cyprus $\left(\mathcal{I}=0.940, \tilde{t}=8.77, \mathcal{S}(\tilde{t})=0.074, R^{i}\left(t_{c}\right)=0.965, R\left(t_{c}\right)=0.861\right)$ and Cyprus $\left(\tilde{t}=8.77, \mathcal{S}(\tilde{t})=0.074, R^{i}\left(t_{c}\right)=0.965\right.$, $\left.R\left(t_{c}\right)=0.878\right)$ 
medRxiv preprint doi: https://doi.org/10.1101/2020.08.01.20165142; this version posted June 14, 2021. The copyright holder for this preprint (which was not certified by peer review) is the author/funder, who has granted medRxiv a license to display the preprint in perpetuity.

It is made available under a CC-BY-NC-ND 4.0 International license .
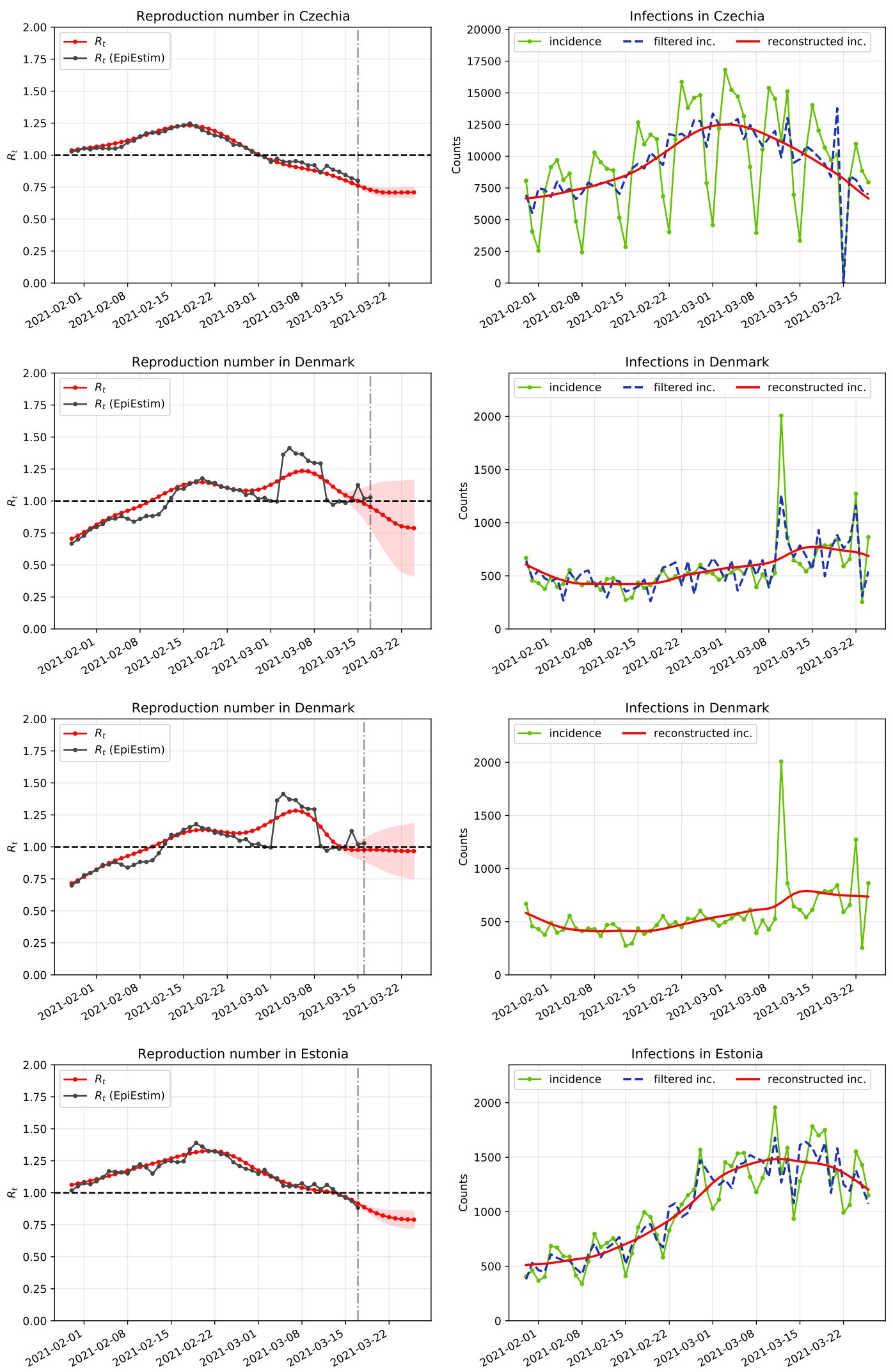

Fig. S7. From top to down: Czechia $\left(\mathcal{I}=0.433, \tilde{t}=9.39, \mathcal{S}(\tilde{t})=0.026, R^{i}\left(t_{c}\right)=0.795, R\left(t_{c}\right)=0.709\right)$, Denmark $(\mathcal{I}=0.717, \tilde{t}=7.42, \mathcal{S}(\tilde{t})=0.080$, $\left.R^{i}\left(t_{c}\right)=1.029, R\left(t_{c}\right)=0.788\right)$ and Denmark $\left(\tilde{t}=8.00, \mathcal{S}(\tilde{t})=0.074, R^{i}\left(t_{c}\right)=1.029, R\left(t_{c}\right)=0.967\right)$, Estonia $(\mathcal{I}=0.661, \tilde{t}=8.81, \mathcal{S}(\tilde{t})=0.029$, $\left.R^{i}\left(t_{c}\right)=0.883, R\left(t_{c}\right)=0.790\right)$. 
medRxiv preprint doi: https://doi.org/10.1101/2020.08.01.20165142; this version posted June 14, 2021. The copyright holder for this preprint (which was not certified by peer review) is the author/funder, who has granted medRxiv a license to display the preprint in perpetuity.

It is made available under a CC-BY-NC-ND 4.0 International license .
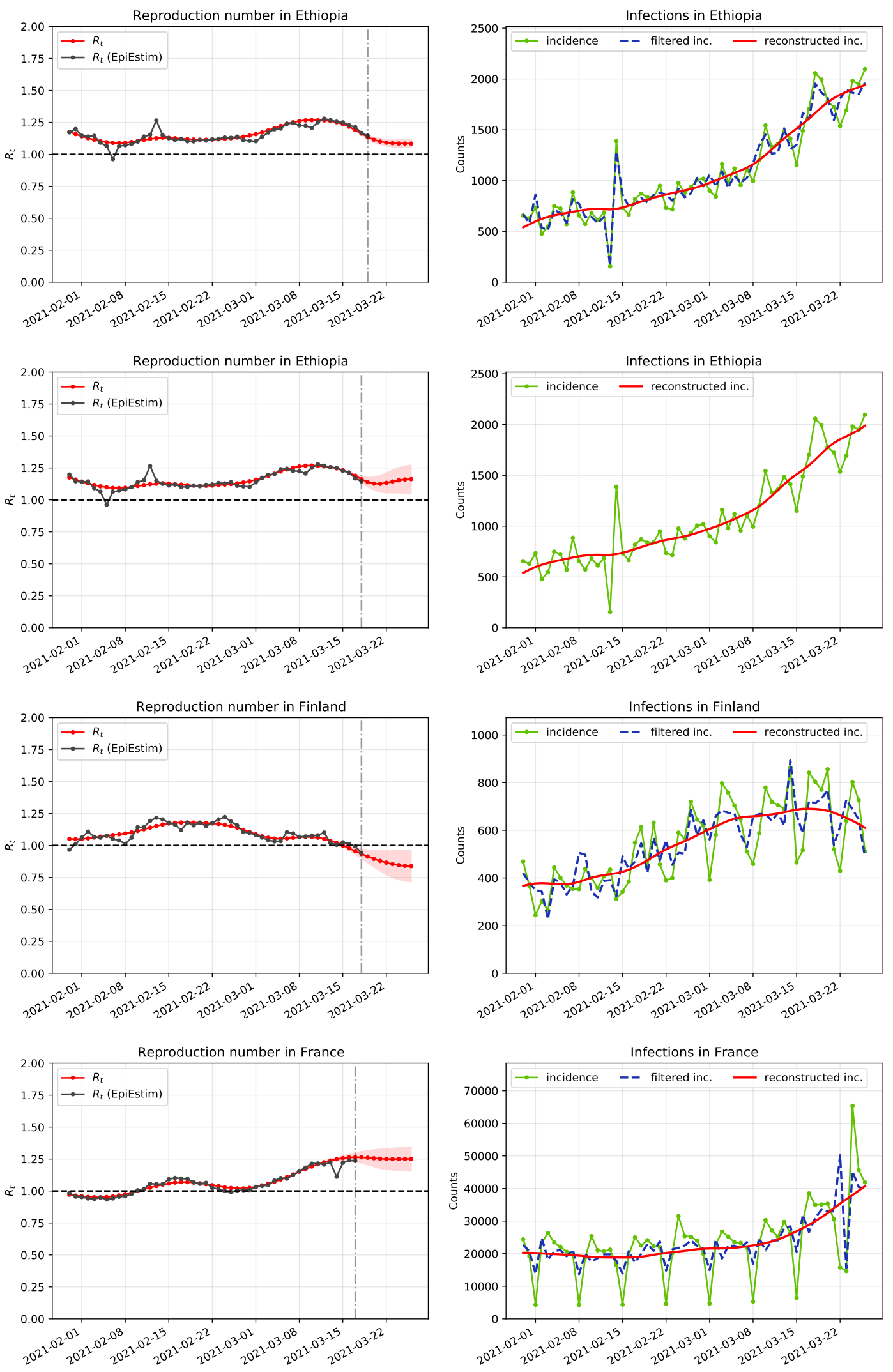

Fig. S8. From top to down: Ethiopia $\left(\mathcal{I}=0.831, \tilde{t}=7.43, \mathcal{S}(\tilde{t})=0.049, R^{i}\left(t_{c}\right)=1.146, R\left(t_{c}\right)=1.084\right)$, Ethiopia $\left(\tilde{t}=7.50, \mathcal{S}(\tilde{t})=0.050, R^{i}\left(t_{c}\right)=1.146\right.$, $\left.R\left(t_{c}\right)=1.162\right)$, Finland $\left(\mathcal{I}=0.630, \tilde{t}=8.00, \mathcal{S}(\tilde{t})=0.038, R^{i}\left(t_{c}\right)=0.941, R\left(t_{c}\right)=0.838\right)$ and France $\left(\mathcal{I}=0.513, \tilde{t}=9.05, \mathcal{S}(\tilde{t})=0.025, R^{i}\left(t_{c}\right)=1.236\right.$, $\left.R\left(t_{c}\right)=1.251\right)$ 
medRxiv preprint doi: https://doi.org/10.1101/2020.08.01.20165142; this version posted June 14, 2021. The copyright holder for this preprint (which was not certified by peer review) is the author/funder, who has granted medRxiv a license to display the preprint in perpetuity.

It is made available under a CC-BY-NC-ND 4.0 International license .
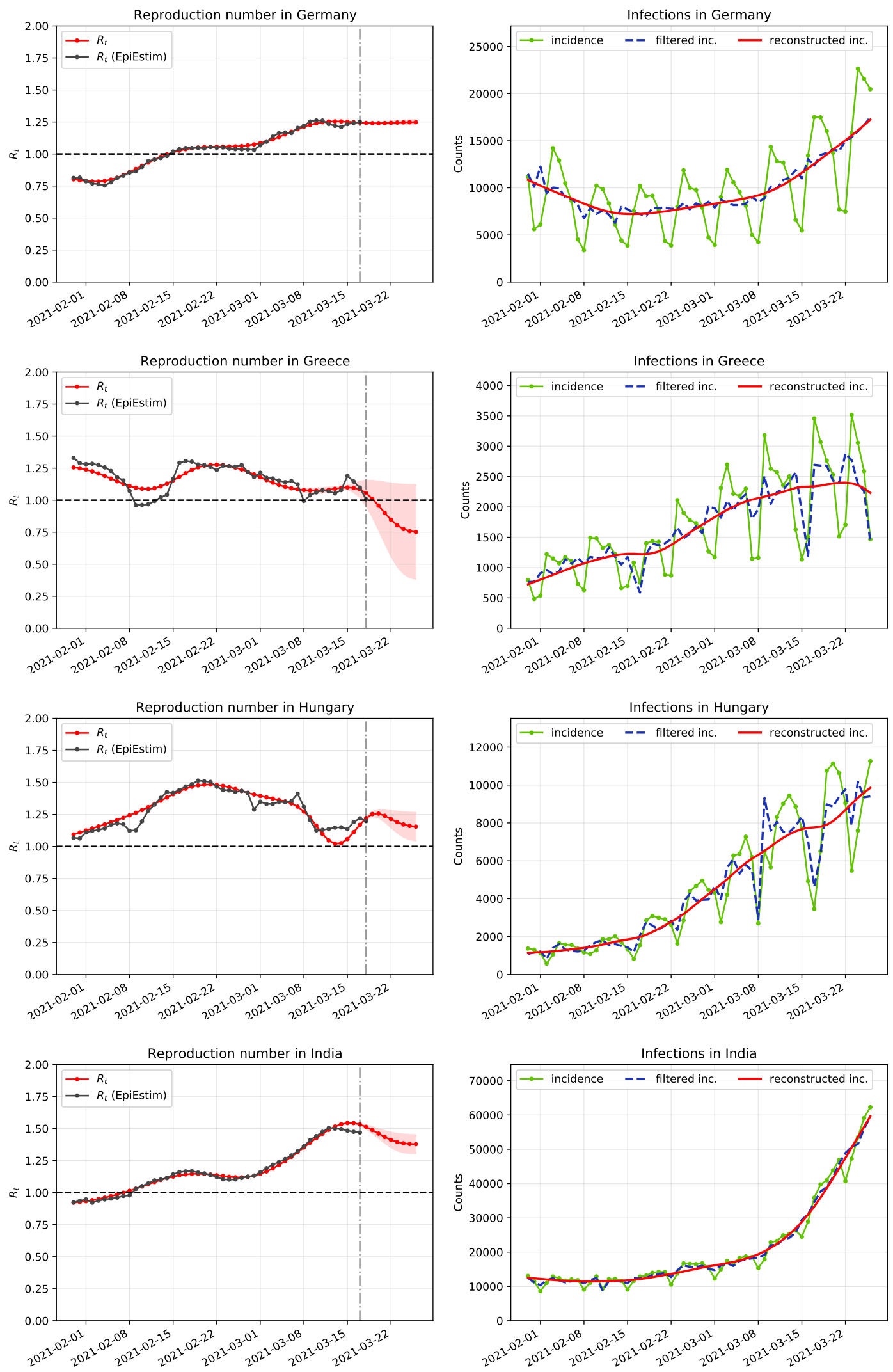

Fig. S9. From top to down: Germany $\left(\mathcal{I}=0.166, \tilde{t}=9.00, \mathcal{S}(\tilde{t})=0.018, R^{i}\left(t_{c}\right)=1.251, R\left(t_{c}\right)=1.249\right)$, Greece $(\mathcal{I}=0.507, \tilde{t}=8.00, \mathcal{S}(\tilde{t})=0.061$, $\left.R^{i}\left(t_{c}\right)=1.007, R\left(t_{c}\right)=0.752\right)$, Hungary $\left(\mathcal{I}=0.644, \tilde{t}=8.15, \mathcal{S}(\tilde{t})=0.052, R^{i}\left(t_{c}\right)=1.198, R\left(t_{c}\right)=1.155\right)$ and India $(\mathcal{I}=0.434, \tilde{t}=8.59, \mathcal{S}(\tilde{t})=0.022$ $\left.R^{i}\left(t_{c}\right)=1.470, R\left(t_{c}\right)=1.378\right)$. 
medRxiv preprint doi: https://doi.org/10.1101/2020.08.01.20165142; this version posted June 14, 2021. The copyright holder for this preprint (which was not certified by peer review) is the author/funder, who has granted medRxiv a license to display the preprint in perpetuity.

It is made available under a CC-BY-NC-ND 4.0 International license .
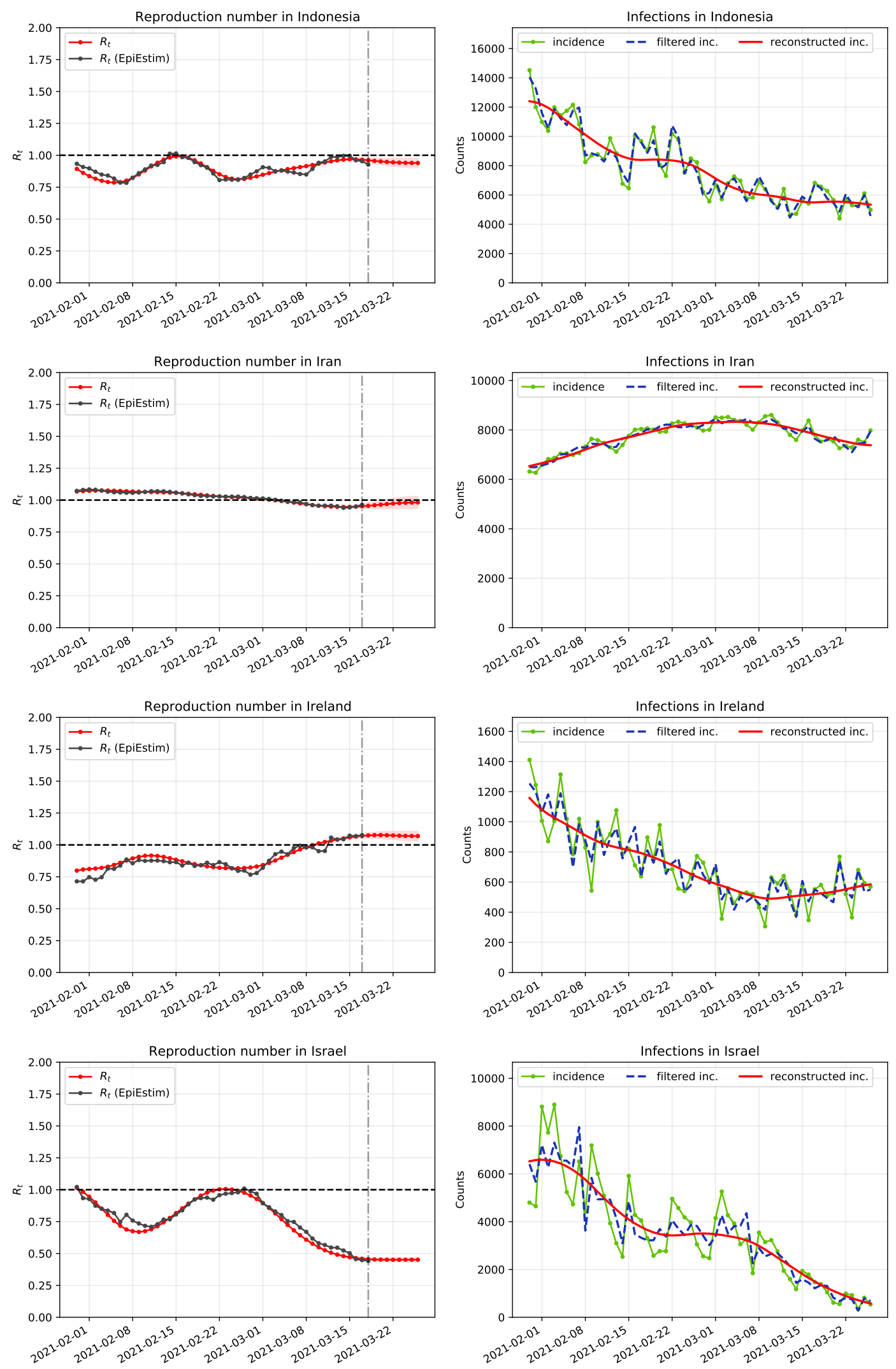

Fig. S10. From top to down: Indonesia $\left(\mathcal{I}=0.890, \tilde{t}=8.18, \mathcal{S}(\tilde{t})=0.029, R^{i}\left(t_{c}\right)=0.927, R\left(t_{c}\right)=0.939\right)$, $\operatorname{Iran}(\mathcal{I}=0.676, \tilde{t}=9.11, \mathcal{S}(\tilde{t})=0.006$, $\left.R^{i}\left(t_{c}\right)=0.963, R\left(t_{c}\right)=0.982\right)$, Ireland $\left(\mathcal{I}=0.730, \tilde{t}=8.57, \mathcal{S}(\tilde{t})=0.045, R^{i}\left(t_{c}\right)=1.075, R\left(t_{c}\right)=1.069\right)$ and Israel $(\mathcal{I}=0.570, \tilde{t}=8.45, \mathcal{S}(\tilde{t})=0.042$, $\left.R^{i}\left(t_{c}\right)=0.442, R\left(t_{c}\right)=0.451\right)$. 
medRxiv preprint doi: https://doi.org/10.1101/2020.08.01.20165142; this version posted June 14, 2021. The copyright holder for this preprint (which was not certified by peer review) is the author/funder, who has granted medRxiv a license to display the preprint in perpetuity.

It is made available under a CC-BY-NC-ND 4.0 International license .
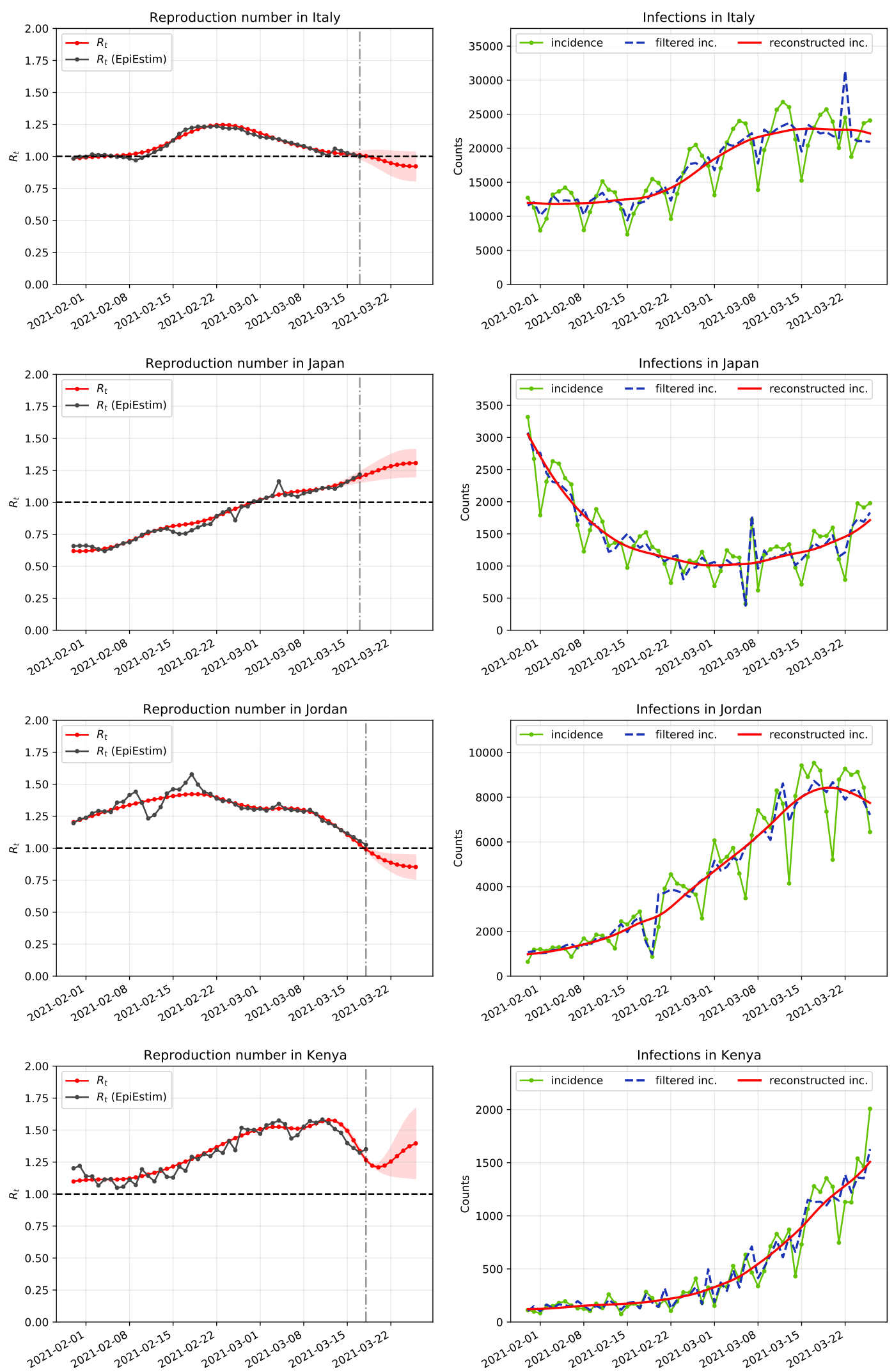

Fig. S11. From top to down: Italy $\left(\mathcal{I}=0.584, \tilde{t}=8.74, \mathcal{S}(\tilde{t})=0.020, R^{i}\left(t_{c}\right)=1.001, R\left(t_{c}\right)=0.922\right)$, Japan $(\mathcal{I}=0.570, \tilde{t}=8.93, \mathcal{S}(\tilde{t})=0.041$, $\left.R^{i}\left(t_{c}\right)=1.216, R\left(t_{c}\right)=1.307\right)$, Jordan $\left(\mathcal{I}=0.437, \tilde{t}=8.00, \mathcal{S}(\tilde{t})=0.047, R^{i}\left(t_{c}\right)=1.027, R\left(t_{c}\right)=0.853\right)$ and Kenya $(\mathcal{I}=0.574, \tilde{t}=7.91, \mathcal{S}(\tilde{t})=0.056$ $\left.R^{i}\left(t_{c}\right)=1.351, R\left(t_{c}\right)=1.396\right)$. 
medRxiv preprint doi: https://doi.org/10.1101/2020.08.01.20165142; this version posted June 14, 2021. The copyright holder for this preprint (which was not certified by peer review) is the author/funder, who has granted medRxiv a license to display the preprint in perpetuity.

It is made available under a CC-BY-NC-ND 4.0 International license .
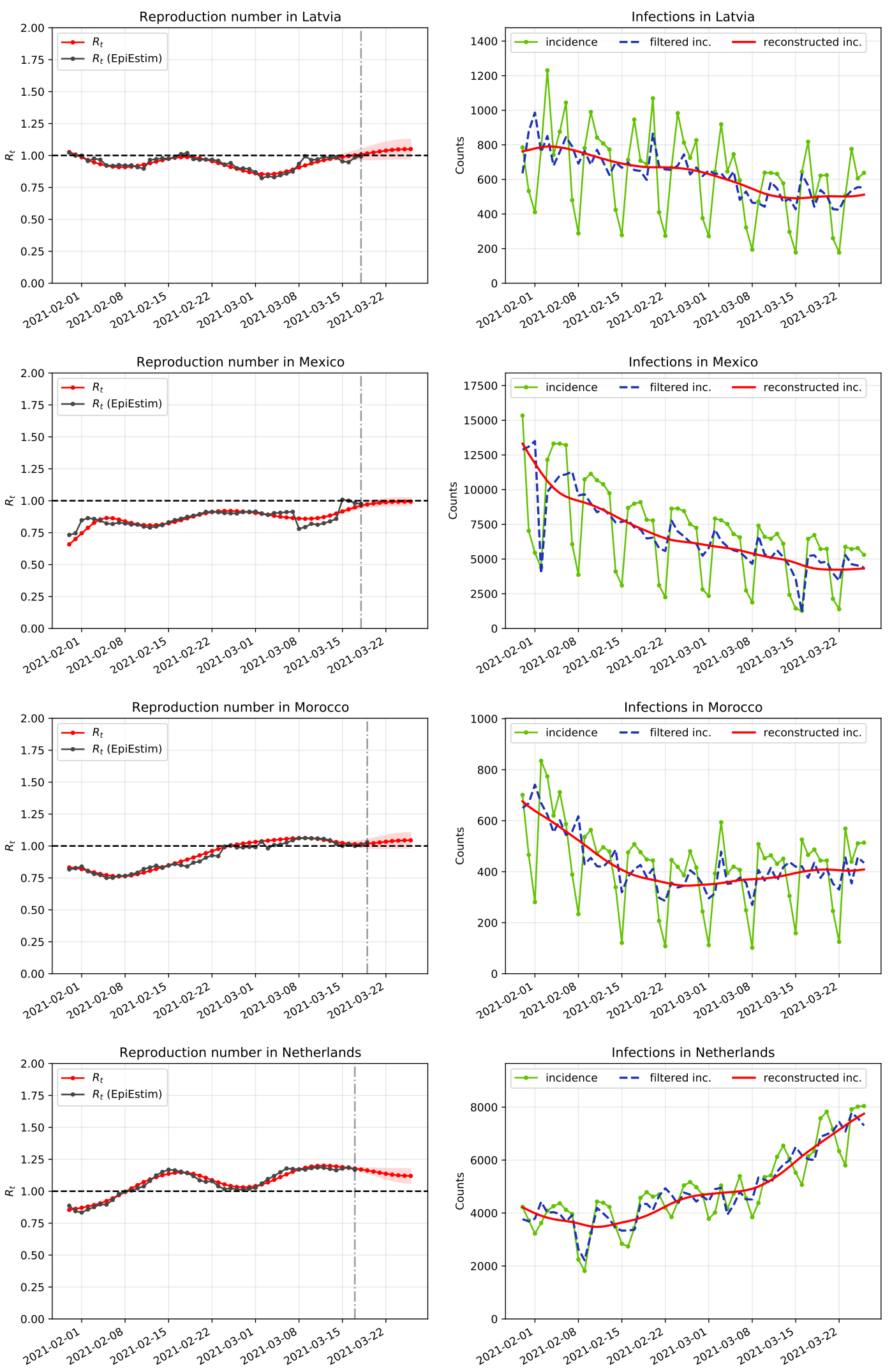

Fig. S12. From top to down: Latvia $\left(\mathcal{I}=0.299, \tilde{t}=8.43, \mathcal{S}(\tilde{t})=0.026, R^{i}\left(t_{c}\right)=0.993, R\left(t_{c}\right)=1.050\right)$, Mexico $(\mathcal{I}=0.449, \tilde{t}=8.46, \mathcal{S}(\tilde{t})=0.051$, $\left.R^{i}\left(t_{c}\right)=0.976, R\left(t_{c}\right)=0.993\right)$, Morocco $\left(\mathcal{I}=0.329, \tilde{t}=7.32, \mathcal{S}(\tilde{t})=0.025, R^{i}\left(t_{c}\right)=1.030, R\left(t_{c}\right)=1.045\right)$ and Netherlands $(\mathcal{I}=0.601, \tilde{t}=8.55$, $\left.\mathcal{S}(\tilde{t})=0.023, R^{i}\left(t_{c}\right)=1.168, R\left(t_{c}\right)=1.120\right)$. 
medRxiv preprint doi: https://doi.org/10.1101/2020.08.01.20165142; this version posted June 14, 2021. The copyright holder for this preprint (which was not certified by peer review) is the author/funder, who has granted medRxiv a license to display the preprint in perpetuity.

It is made available under a CC-BY-NC-ND 4.0 International license .
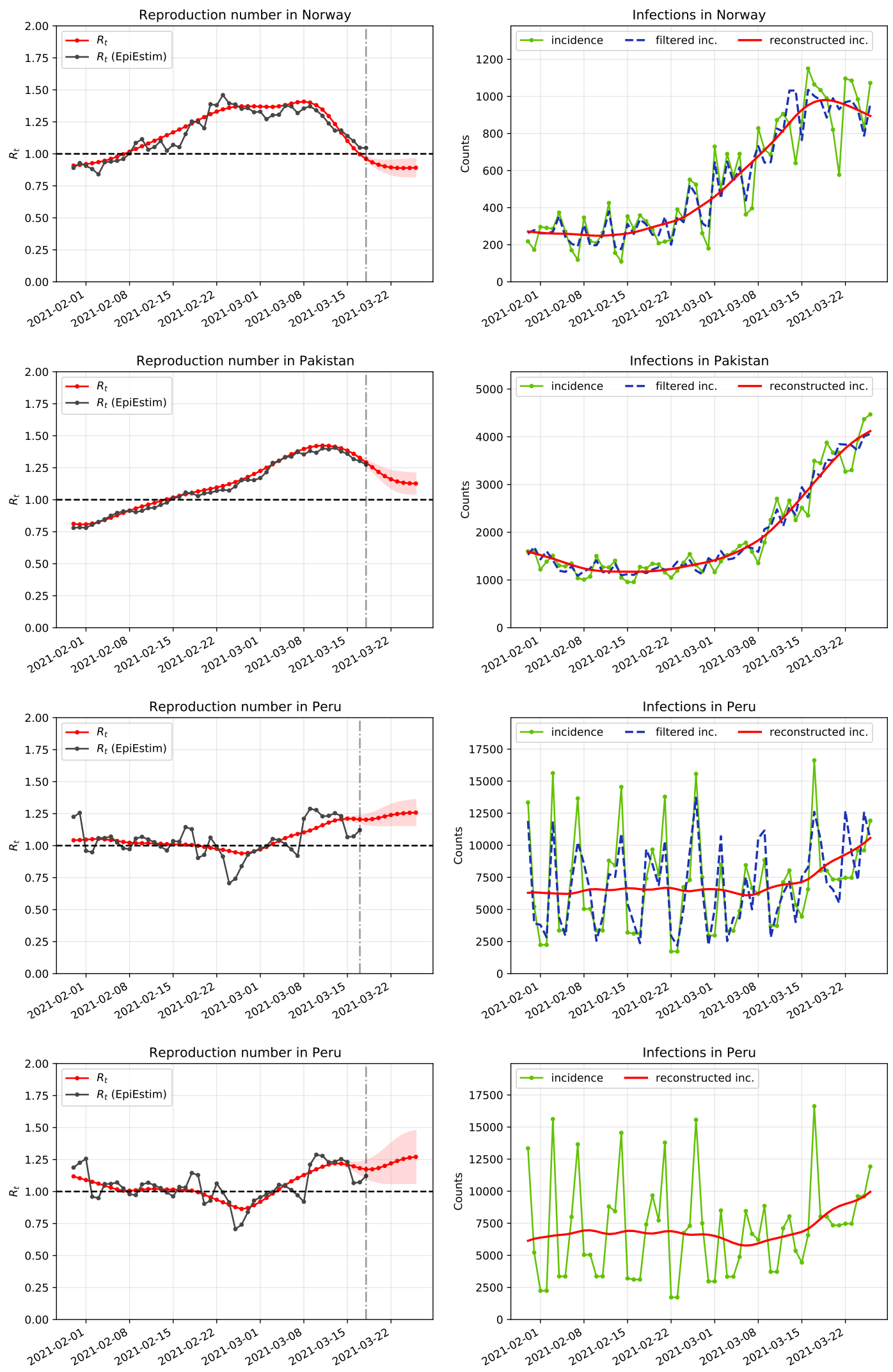

Fig. S13. From top to down: Norway $\left(\mathcal{I}=0.609, \tilde{t}=8.48, \mathcal{S}(\tilde{t})=0.053, R^{i}\left(t_{c}\right)=1.046, R\left(t_{c}\right)=0.891\right)$, Pakistan $(\mathcal{I}=0.557, \tilde{t}=8.37, \mathcal{S}(\tilde{t})=0.027$, $\left.R^{i}\left(t_{c}\right)=1.274, R\left(t_{c}\right)=1.127\right)$, Peru $\left(\mathcal{I}=0.830, \tilde{t}=8.68, \mathcal{S}(\tilde{t})=0.105, R^{i}\left(t_{c}\right)=1.122, R\left(t_{c}\right)=1.258\right)$ and Peru $\left(\tilde{t}=8.02, \mathcal{S}(\tilde{t})=0.088, R^{i}\left(t_{c}\right)=1.122\right.$, $\left.R\left(t_{c}\right)=1.270\right)$. 
medRxiv preprint doi: https://doi.org/10.1101/2020.08.01.20165142; this version posted June 14, 2021. The copyright holder for this preprint (which was not certified by peer review) is the author/funder, who has granted medRxiv a license to display the preprint in perpetuity.

It is made available under a CC-BY-NC-ND 4.0 International license .
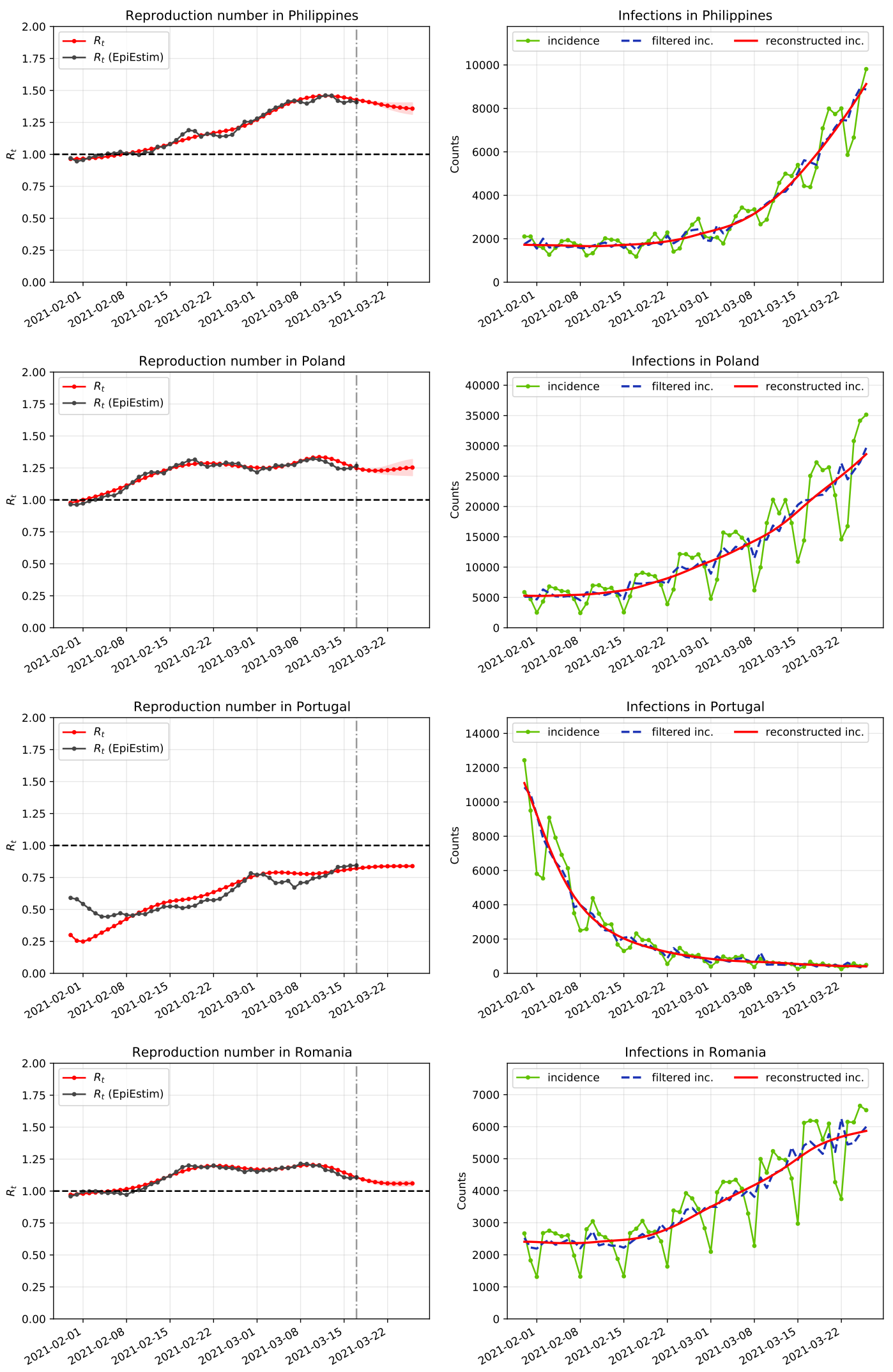

Fig. S14. From top to down: Philippines $\left(\mathcal{I}=0.313, \tilde{t}=8.55, \mathcal{S}(\tilde{t})=0.026, R^{i}\left(t_{c}\right)=1.408, R\left(t_{c}\right)=1.358\right)$, Poland $(\mathcal{I}=0.227, \tilde{t}=8.77, \mathcal{S}(\tilde{t})=0.022$, $\left.R^{i}\left(t_{c}\right)=1.267, R\left(t_{c}\right)=1.253\right)$, Portugal $\left(\mathcal{I}=0.230, \tilde{t}=9.49, \mathcal{S}(\tilde{t})=0.103, R^{i}\left(t_{c}\right)=0.844, R\left(t_{c}\right)=0.839\right)$ and Romania $(\mathcal{I}=0.265, \tilde{t}=8.57$, $\left.\mathcal{S}(\tilde{t})=0.019, R^{i}\left(t_{c}\right)=1.107, R\left(t_{c}\right)=1.060\right)$. 
medRxiv preprint doi: https://doi.org/10.1101/2020.08.01.20165142; this version posted June 14, 2021. The copyright holder for this preprint (which was not certified by peer review) is the author/funder, who has granted medRxiv a license to display the preprint in perpetuity.

It is made available under a CC-BY-NC-ND 4.0 International license .
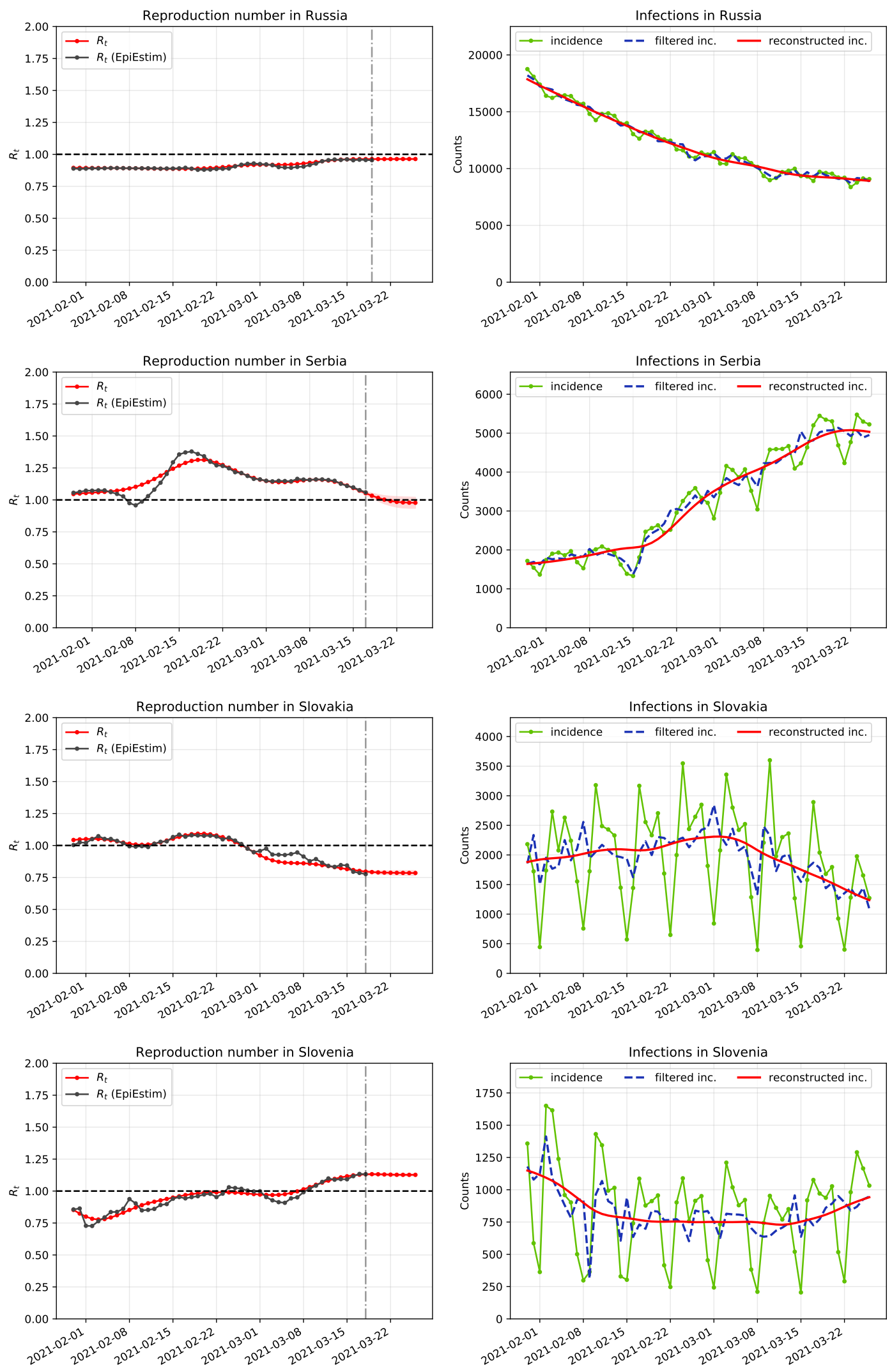

Fig. S15. From top to down: Russia $\left(\mathcal{I}=0.621, \tilde{t}=7.25, \mathcal{S}(\tilde{t})=0.010, R^{i}\left(t_{c}\right)=0.954, R\left(t_{c}\right)=0.963\right)$, Serbia $(\mathcal{I}=0.548, \tilde{t}=8.41, \mathcal{S}(\tilde{t})=0.043$, $\left.R^{i}\left(t_{c}\right)=1.059, R\left(t_{c}\right)=0.978\right)$, Slovakia $\left(\mathcal{I}=0.304, \tilde{t}=8.31, \mathcal{S}(\tilde{t})=0.029, R^{i}\left(t_{c}\right)=0.776, R\left(t_{c}\right)=0.785\right)$ and Slovenia $(\mathcal{I}=0.354, \tilde{t}=7.88$ $\left.\mathcal{S}(\tilde{t})=0.034, R^{i}\left(t_{c}\right)=1.132, R\left(t_{c}\right)=1.127\right)$. 
medRxiv preprint doi: https://doi.org/10.1101/2020.08.01.20165142; this version posted June 14, 2021. The copyright holder for this preprint (which was not certified by peer review) is the author/funder, who has granted medRxiv a license to display the preprint in perpetuity.

It is made available under a CC-BY-NC-ND 4.0 International license .
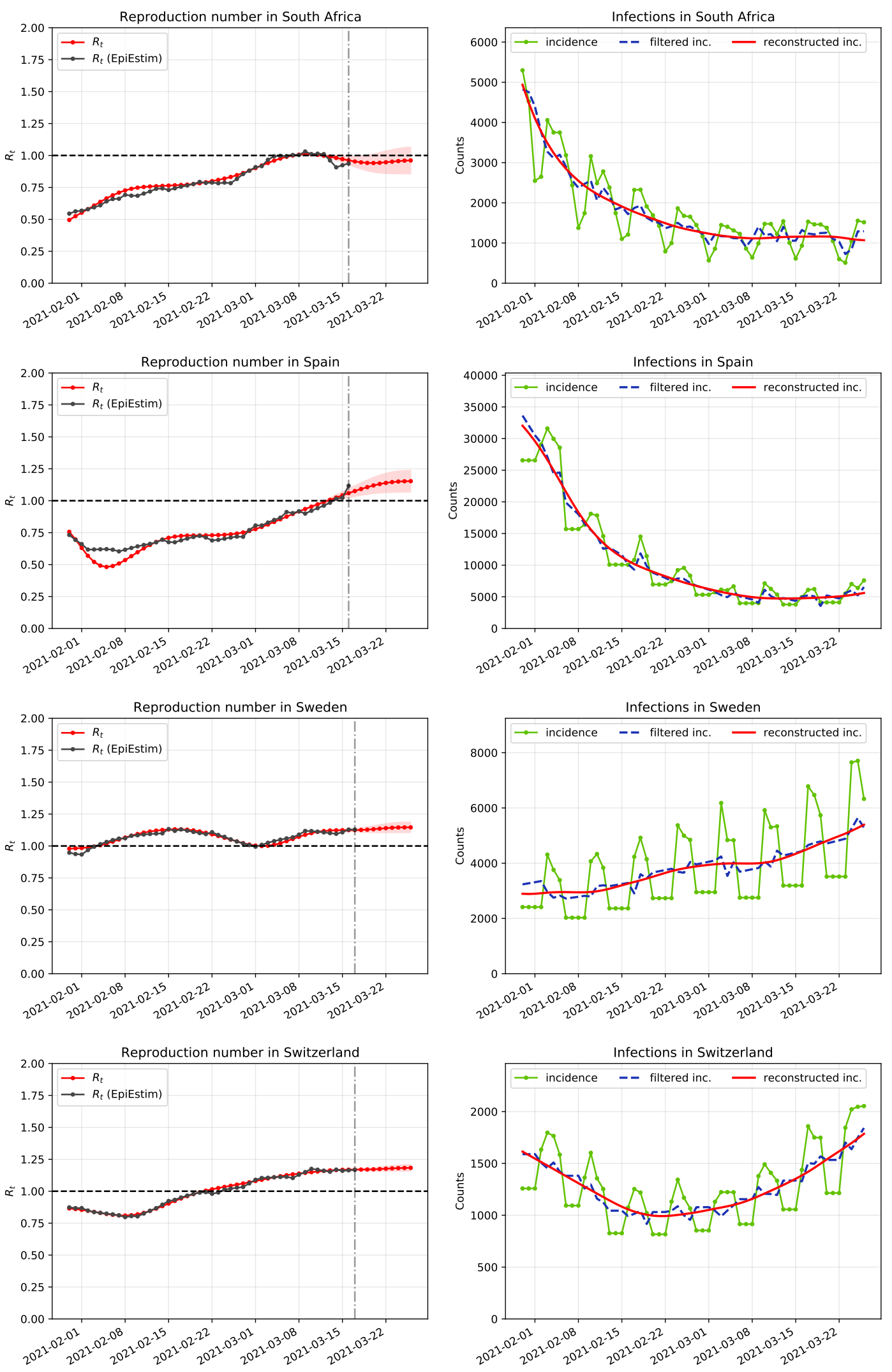

Fig. S16. From top to down: South Africa $\left(\mathcal{I}=0.299, \tilde{t}=10.42, \mathcal{S}(\tilde{t})=0.055, R^{i}\left(t_{c}\right)=0.937, R\left(t_{c}\right)=0.961\right)$, Spain $(\mathcal{I}=0.290, \tilde{t}=9.70, \mathcal{S}(\tilde{t})=0.046$, $\left.R^{i}\left(t_{c}\right)=1.117, R\left(t_{c}\right)=1.153\right)$, Sweden $\left(\mathcal{I}=0.192, \tilde{t}=9.45, \mathcal{S}(\tilde{t})=0.022, R^{i}\left(t_{c}\right)=1.128, R\left(t_{c}\right)=1.146\right)$ and Switzerland $(\mathcal{I}=0.206, \tilde{t}=9.10$ $\left.\mathcal{S}(\tilde{t})=0.016, R^{i}\left(t_{c}\right)=1.167, R\left(t_{c}\right)=1.183\right)$. 
medRxiv preprint doi: https://doi.org/10.1101/2020.08.01.20165142; this version posted June 14, 2021. The copyright holder for this preprint (which was not certified by peer review) is the author/funder, who has granted medRxiv a license to display the preprint in perpetuity.

It is made available under a CC-BY-NC-ND 4.0 International license .
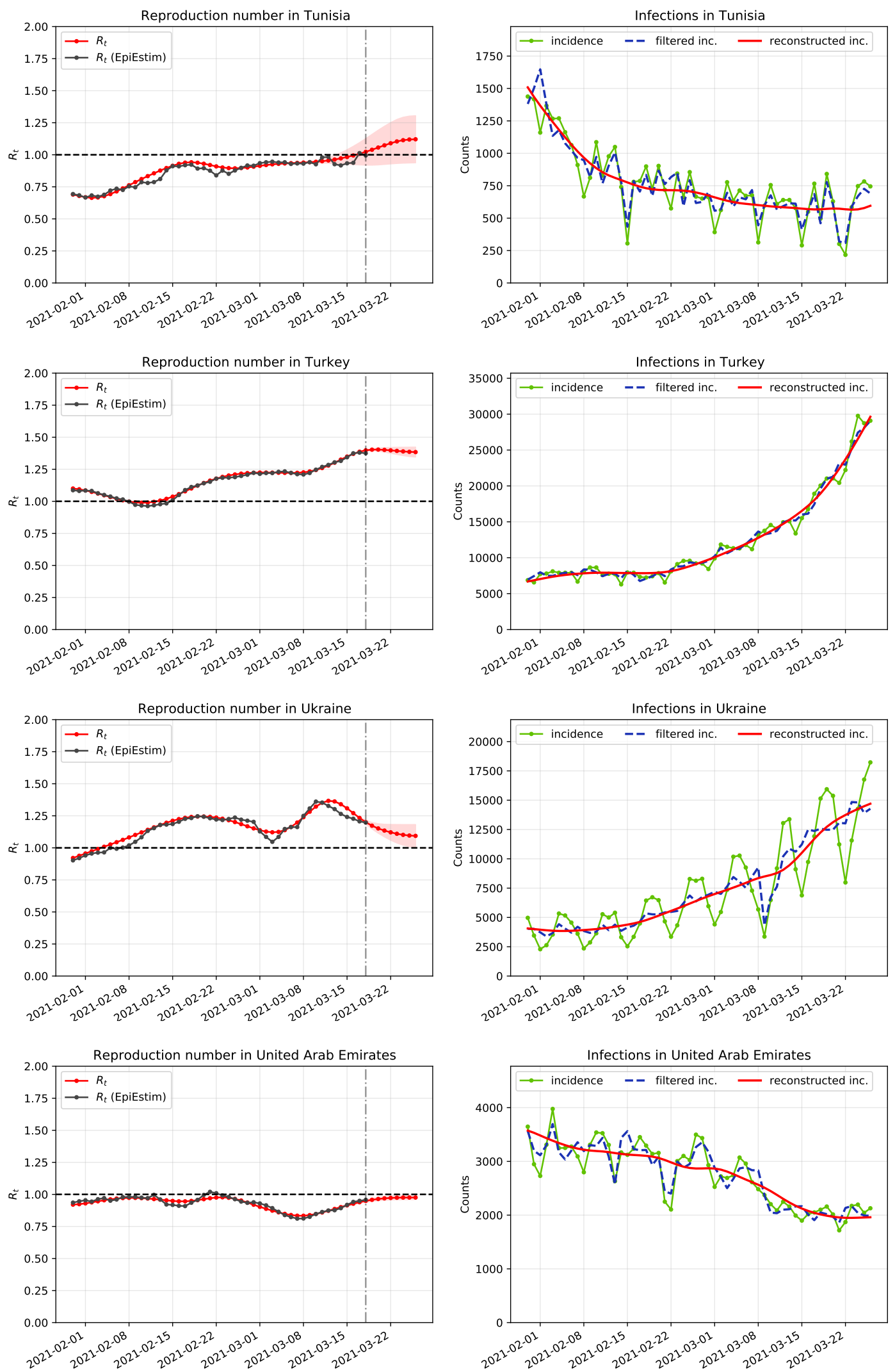

Fig. S17. From top to down: Tunisia $\left(\mathcal{I}=0.738, \tilde{t}=8.19, \mathcal{S}(\tilde{t})=0.038, R^{i}\left(t_{c}\right)=0.995, R\left(t_{c}\right)=1.121\right)$, Turkey $(\mathcal{I}=0.554, \tilde{t}=8.32, \mathcal{S}(\tilde{t})=0.013$, $\left.R^{i}\left(t_{c}\right)=1.375, R\left(t_{c}\right)=1.384\right)$, Ukraine $\left(\mathcal{I}=0.384, \tilde{t}=8.07, \mathcal{S}(\tilde{t})=0.034, R^{i}\left(t_{c}\right)=1.197, R\left(t_{c}\right)=1.093\right)$ and United Arab Emirates $(\mathcal{I}=0.773, \tilde{t}=8.41$, $\left.\mathcal{S}(\tilde{t})=0.021, R^{i}\left(t_{c}\right)=0.957, R\left(t_{c}\right)=0.975\right)$. 
medRxiv preprint doi: https://doi.org/10.1101/2020.08.01.20165142; this version posted June 14, 2021. The copyright holder for this preprint (which was not certified by peer review) is the author/funder, who has granted medRxiv a license to display the preprint in perpetuity.

It is made available under a CC-BY-NC-ND 4.0 International license .
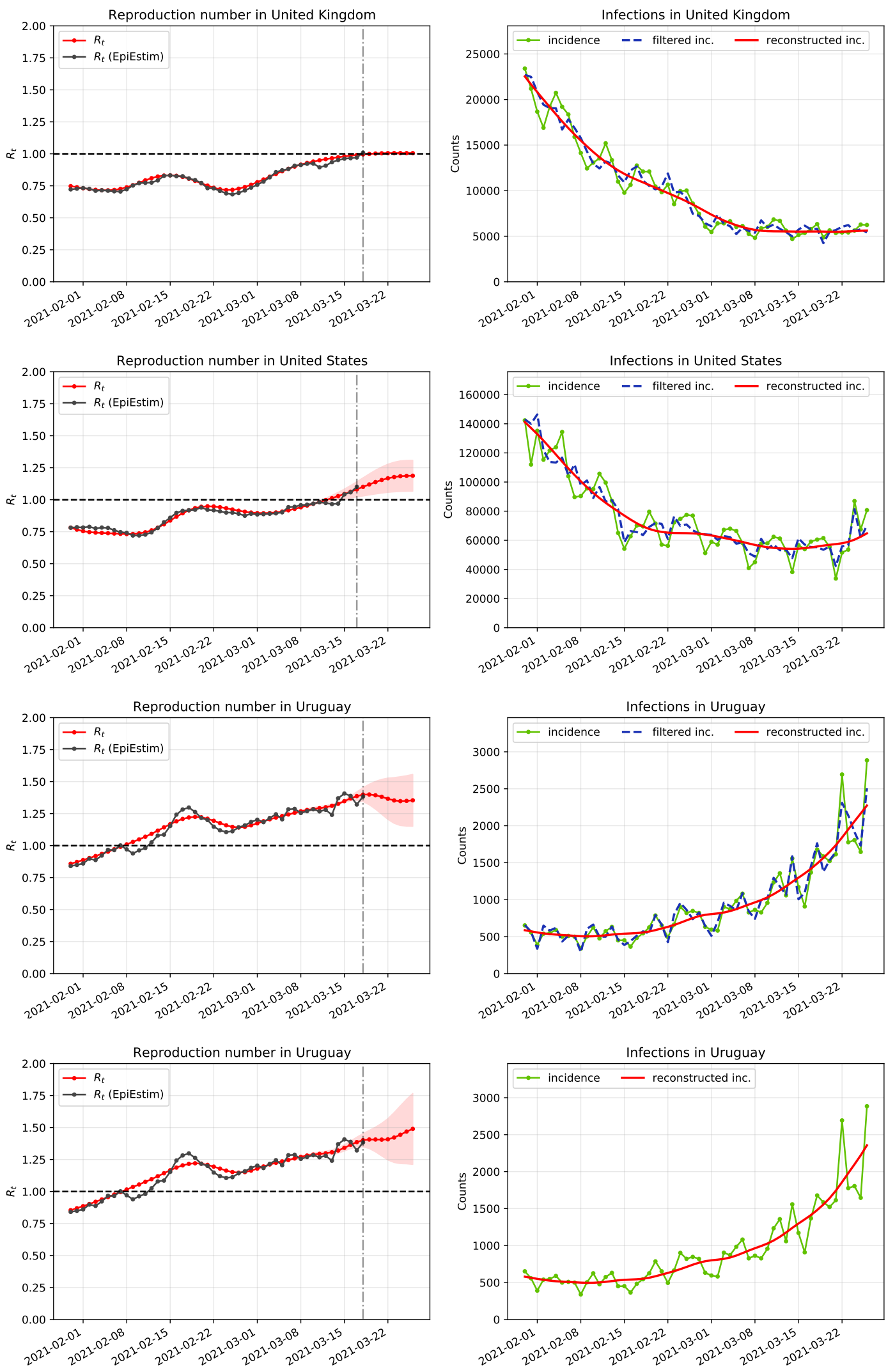

Fig. S18. From top to down: United Kingdom $\left(\mathcal{I}=0.557, \tilde{t}=8.26, \mathcal{S}(\tilde{t})=0.024, R^{i}\left(t_{c}\right)=1.009, R\left(t_{c}\right)=1.006\right)$, USA $(\mathcal{I}=0.569, \tilde{t}=8.76, \mathcal{S}(\tilde{t})=0.023$, $\left.R^{i}\left(t_{c}\right)=1.100, R\left(t_{c}\right)=1.188\right)$, Uruguay $\left(\mathcal{I}=0.822, \tilde{t}=8.26, \mathcal{S}(\tilde{t})=0.039, R^{i}\left(t_{c}\right)=1.384, R\left(t_{c}\right)=1.354\right)$ and Uruguay $(\tilde{t}=8.34, \mathcal{S}(\tilde{t})=0.041$, $\left.R^{i}\left(t_{c}\right)=1.384, R\left(t_{c}\right)=1.489\right)$. 
medRxiv preprint doi: https://doi.org/10.1101/2020.08.01.20165142; this version posted June 14, 2021. The copyright holder for this preprint (which was not certified by peer review) is the author/funder, who has granted medRxiv a license to display the preprint in perpetuity.

It is made available under a CC-BY-NC-ND 4.0 International license .
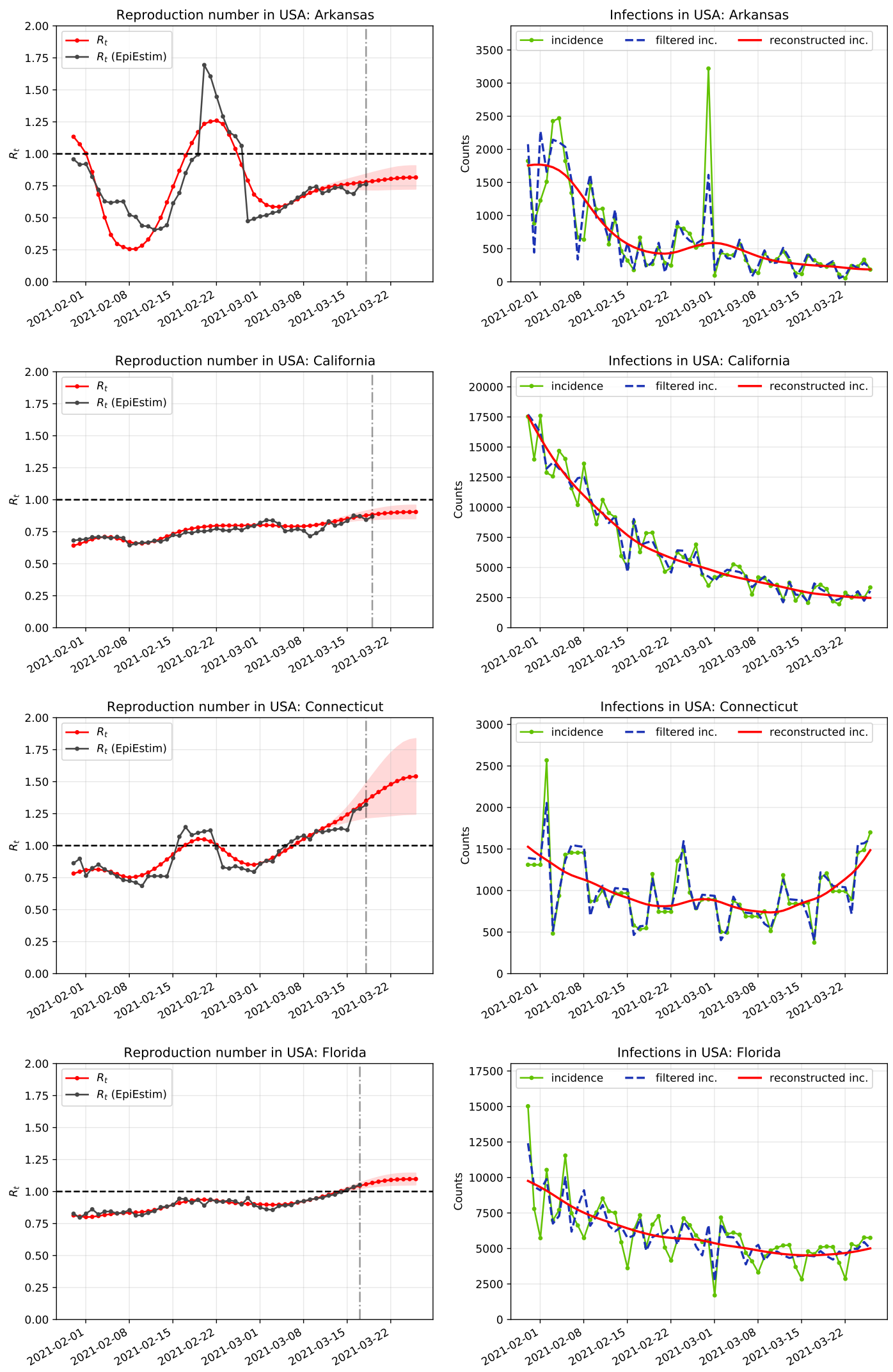

Fig. S19. From top to down: Arkansas $\left(\mathcal{I}=0.753, \tilde{t}=8.46, \mathcal{S}(\tilde{t})=0.155, R^{i}\left(t_{c}\right)=0.762, R\left(t_{c}\right)=0.816\right)$, California $(\mathcal{I}=0.692, \tilde{t}=6.72, \mathcal{S}(\tilde{t})=0.033$, $\left.R^{i}\left(t_{c}\right)=0.868, R\left(t_{c}\right)=0.904\right)$, Connecticut $\left(\mathcal{I}=0.936, \tilde{t}=8.00, \mathcal{S}(\tilde{t})=0.061, R^{i}\left(t_{c}\right)=1.320, R\left(t_{c}\right)=1.541\right)$ and Florida $(\mathcal{I}=0.606, \tilde{t}=8.74$, $\left.\mathcal{S}(\tilde{t})=0.021, R^{i}\left(t_{c}\right)=1.052, R\left(t_{c}\right)=1.098\right)$. 
medRxiv preprint doi: https://doi.org/10.1101/2020.08.01.20165142; this version posted June 14, 2021. The copyright holder for this preprint (which was not certified by peer review) is the author/funder, who has granted medRxiv a license to display the preprint in perpetuity.

It is made available under a CC-BY-NC-ND 4.0 International license .
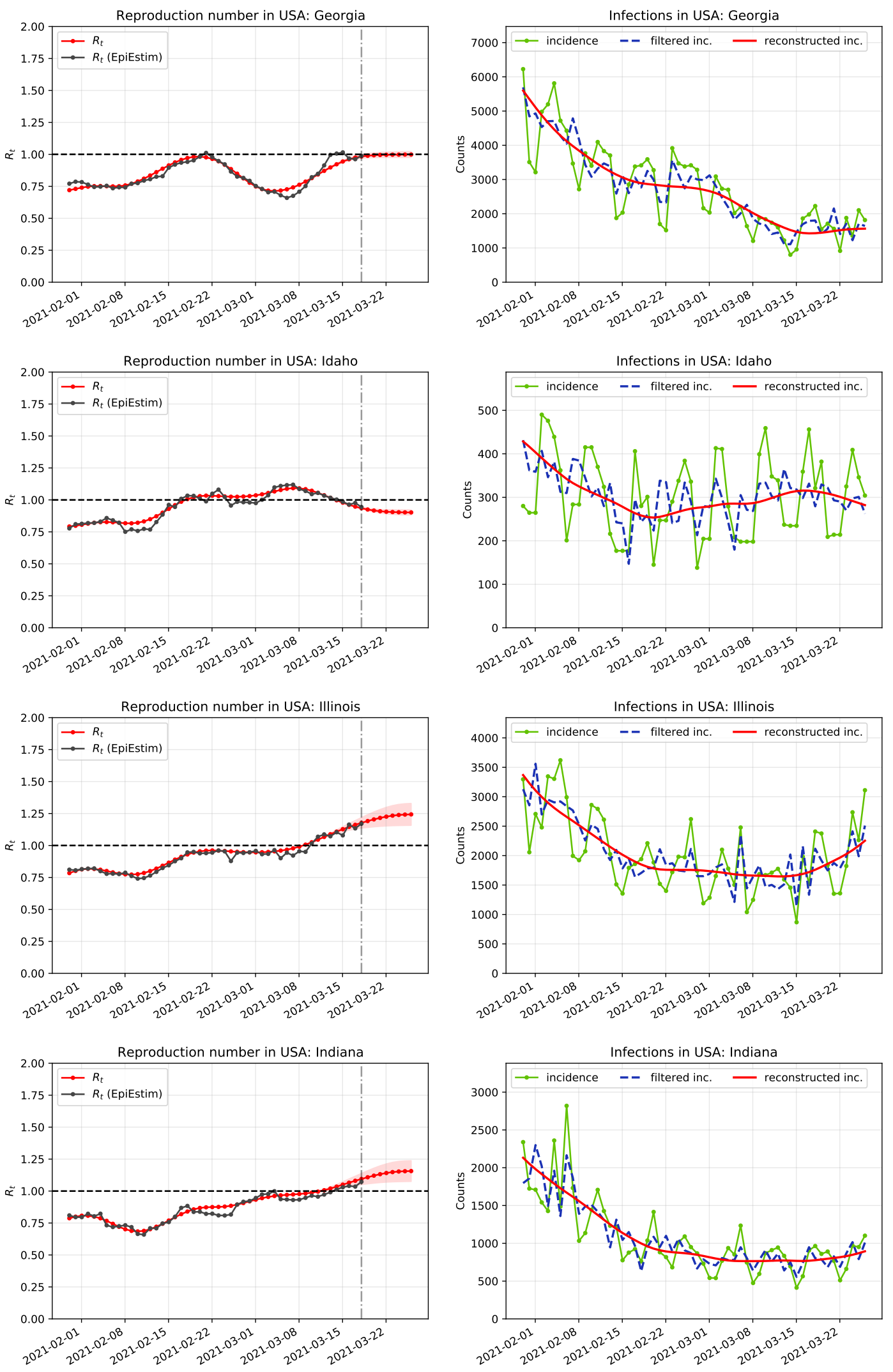

Fig. S20. From top to down: Georgia $\left(\mathcal{I}=0.463, \tilde{t}=8.13, \mathcal{S}(\tilde{t})=0.035, R^{i}\left(t_{c}\right)=0.988, R\left(t_{c}\right)=0.998\right)$, Idaho $(\mathcal{I}=0.450, \tilde{t}=8.02, \mathcal{S}(\tilde{t})=0.034$, $\left.R^{i}\left(t_{c}\right)=0.944, R\left(t_{c}\right)=0.902\right)$, Illinois $\left(\mathcal{I}=0.516, \tilde{t}=8.25, \mathcal{S}(\tilde{t})=0.026, R^{i}\left(t_{c}\right)=1.170, R\left(t_{c}\right)=1.243\right)$ and Indiana $(\mathcal{I}=0.586, \tilde{t}=8.31, \mathcal{S}(\tilde{t})=0.031$, $\left.R^{i}\left(t_{c}\right)=1.073, R\left(t_{c}\right)=1.156\right)$. 
medRxiv preprint doi: https://doi.org/10.1101/2020.08.01.20165142; this version posted June 14, 2021. The copyright holder for this preprint (which was not certified by peer review) is the author/funder, who has granted medRxiv a license to display the preprint in perpetuity.

It is made available under a CC-BY-NC-ND 4.0 International license .
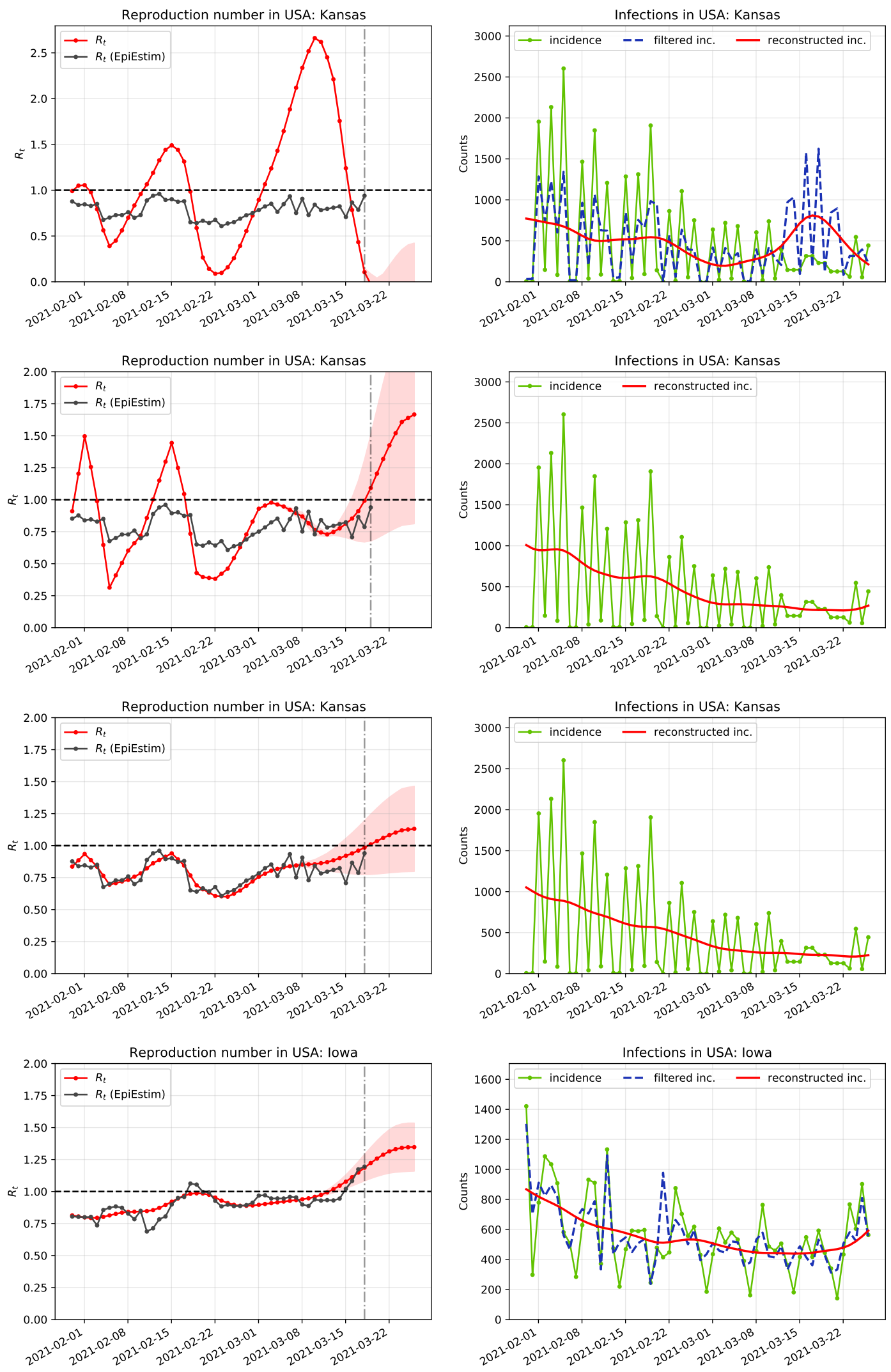

Fig. S21. From top to down: Kansas $\left(\mathcal{I}=0.595, \tilde{t}=8.50, \mathcal{S}(\tilde{t})=0.692, R^{i}\left(t_{c}\right)=0.940, R\left(t_{c}\right)=-0.022, \mathcal{V}(i)=1.728\right)$, Kansas $(\tilde{t}=7.42, \mathcal{S}(\tilde{t})=0.205$, $\left.R^{i}\left(t_{c}\right)=0.940, R\left(t_{c}\right)=1.666\right)$, Kansas $\left(\tilde{t}=7.59, \mathcal{S}(\tilde{t})=0.065, R^{i}\left(t_{c}\right)=0.940, R\left(t_{c}\right)=1.131, w=40\right)$ and lowa $(\mathcal{I}=0.707, \tilde{t}=8.49, \mathcal{S}(\tilde{t})=0.055$ $\left.R^{i}\left(t_{c}\right)=1.195 . R\left(t_{c}\right)=1.347\right)$ 
medRxiv preprint doi: https://doi.org/10.1101/2020.08.01.20165142; this version posted June 14, 2021. The copyright holder for this preprint (which was not certified by peer review) is the author/funder, who has granted medRxiv a license to display the preprint in perpetuity.

It is made available under a CC-BY-NC-ND 4.0 International license .
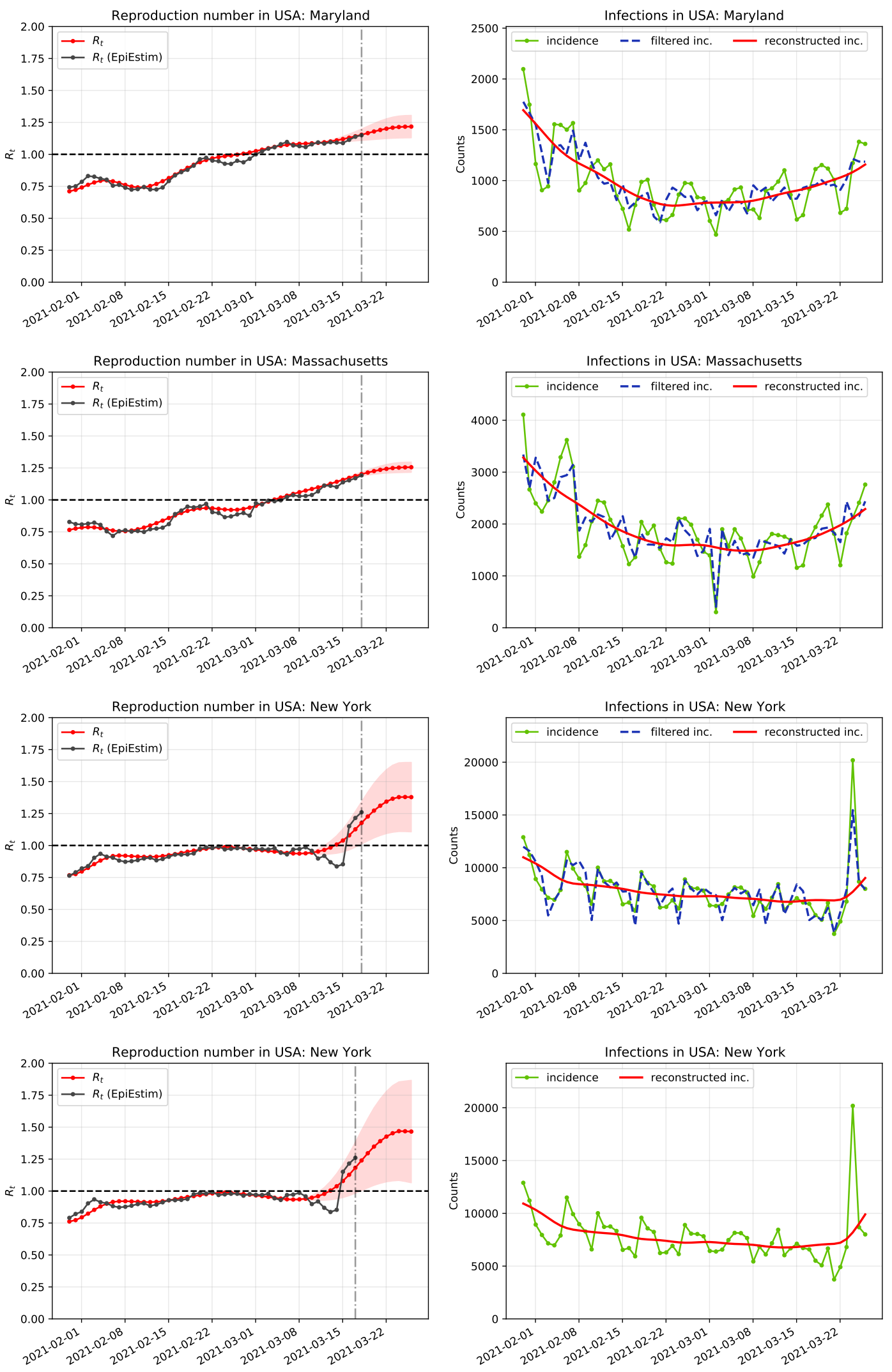

Fig. S22. From top to down: $\operatorname{Maryland}\left(\mathcal{I}=0.525, \tilde{t}=8.20, \mathcal{S}(\tilde{t})=0.028, R^{i}\left(t_{c}\right)=1.150, R\left(t_{c}\right)=1.217\right)$, Massachusetts $(\mathcal{I}=0.630, \tilde{t}=8.35, \mathcal{S}(\tilde{t})=0.031$, $\left.R^{i}\left(t_{c}\right)=1.192, R\left(t_{c}\right)=1.256\right)$, New York $\left(\mathcal{I}=0.860, \tilde{t}=8.00, \mathcal{S}(\tilde{t})=0.048, R^{i}\left(t_{c}\right)=1.260, R\left(t_{c}\right)=1.378\right)$ and New York $(\tilde{t}=8.76, \mathcal{S}(\tilde{t})=0.049$, $\left.R^{i}\left(t_{c}\right)=1.260, R\left(t_{c}\right)=1.465\right)$. 
medRxiv preprint doi: https://doi.org/10.1101/2020.08.01.20165142; this version posted June 14, 2021. The copyright holder for this preprint (which was not certified by peer review) is the author/funder, who has granted medRxiv a license to display the preprint in perpetuity.

It is made available under a CC-BY-NC-ND 4.0 International license .
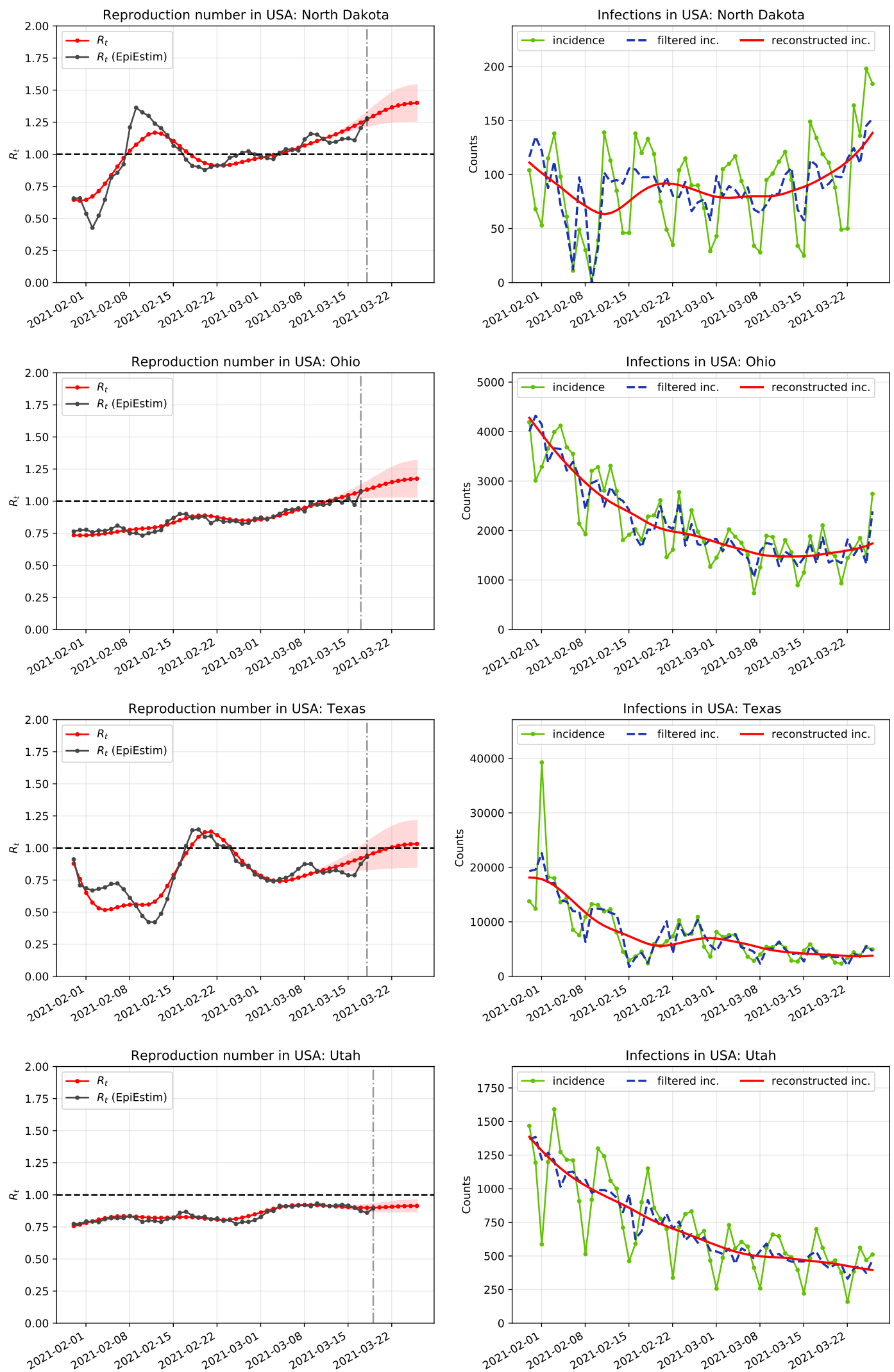

Fig. S23. From top to down: North Dakota $\left(\mathcal{I}=0.537, \tilde{t}=8.00, \mathcal{S}(\tilde{t})=0.086, R^{i}\left(t_{c}\right)=1.279, R\left(t_{c}\right)=1.401\right)$, Ohio $(\mathcal{I}=0.542, \tilde{t}=8.55, \mathcal{S}(\tilde{t})=0.032$, $\left.R^{i}\left(t_{c}\right)=1.077, R\left(t_{c}\right)=1.175\right)$, Texas $\left(\mathcal{I}=0.576, \tilde{t}=7.93, \mathcal{S}(\tilde{t})=0.081, R^{i}\left(t_{c}\right)=0.931, R\left(t_{c}\right)=1.032\right)$ and Utah $(\mathcal{I}=0.292, \tilde{t}=7.06, \mathcal{S}(\tilde{t})=0.023$ $\left.R^{i}\left(t_{c}\right)=0.895, R\left(t_{c}\right)=0.914\right)$. 
medRxiv preprint doi: https://doi.org/10.1101/2020.08.01.20165142; this version posted June 14, 2021. The copyright holder for this preprint (which was not certified by peer review) is the author/funder, who has granted medRxiv a license to display the preprint in perpetuity.

It is made available under a CC-BY-NC-ND 4.0 International license .
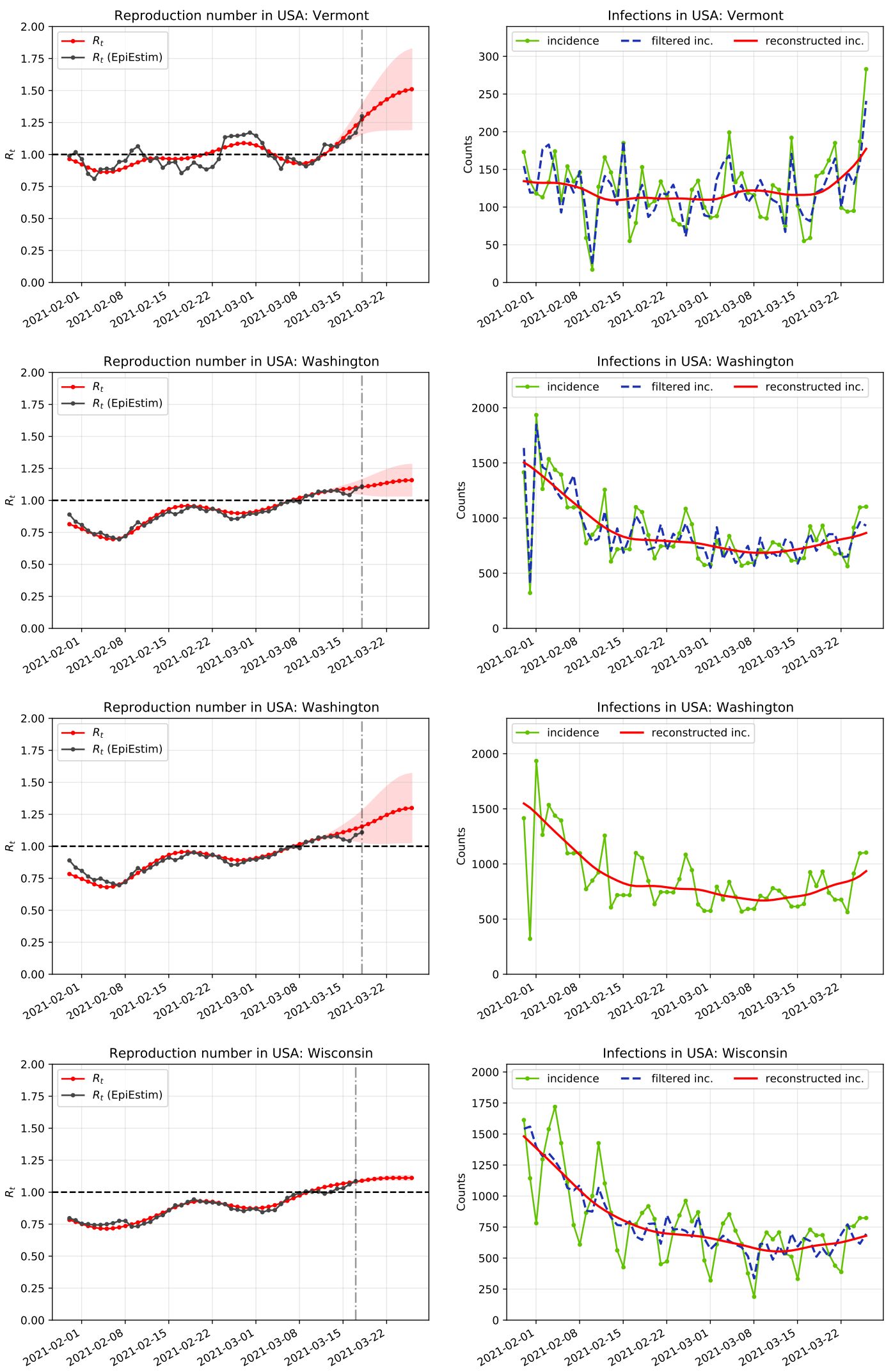

Fig. S24. From top to down: Vermont $\left(\mathcal{I}=0.760, \tilde{t}=8.00, \mathcal{S}(\tilde{t})=0.057, R^{i}\left(t_{c}\right)=1.300, R\left(t_{c}\right)=1.510\right)$, Washington $(\mathcal{I}=0.816, \tilde{t}=8.23, \mathcal{S}(\tilde{t})=0.027$, $\left.R^{i}\left(t_{c}\right)=1.109, R\left(t_{c}\right)=1.158\right)$, Washington $\left(\tilde{t}=8.47, \mathcal{S}(\tilde{t})=0.037, R^{i}\left(t_{c}\right)=1.109, R\left(t_{c}\right)=1.299\right)$ and Wisconsin $(\mathcal{I}=0.344, \tilde{t}=9.29, \mathcal{S}(\tilde{t})=0.027$, $\left.R^{i}\left(t_{c}\right)=1.086, R\left(t_{c}\right)=1.111\right)$. 